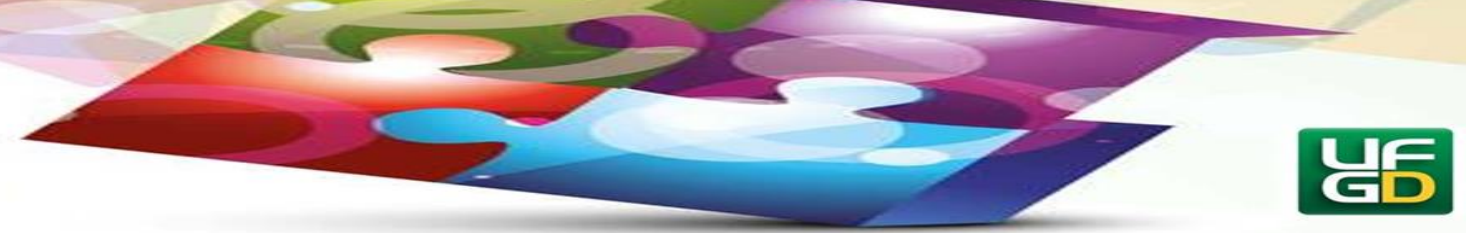

\title{
A INFLUÊNCIA DE ORGANIZAÇÕES DIDÁTICAS NO TRABALHO MATEMÁTICO DOS ESTAGIÁRIOS DA LICENCIATURA: UM ESTUDO NA FORMAÇÃO INICIAL
}

\author{
THE INFLUENCE OF DIDACTIC ORGANIZATIONS IN THE MATHEMATICAL \\ WORK OF LICENSORS: A STUDY IN INITIAL TRAINING
}

Rita Lobo FREITAS ${ }^{1}$

Saddo Ag ALMOULOUD ${ }^{2}$

\begin{abstract}
Resumo: no presente trabalho, relataram-se os principais resultados da pesquisa de mestrado finalizada em 2015. Nesta, investigou-se o processo de aprendizagem dos estudantes de um curso de Licenciatura em Matemática de uma universidade estadual na Bahia, durante as aulas do componente curricular Estágio Supervisionado. O objetivo foi analisar como esses sujeitos mobilizam seus saberes matemáticos a respeito da função exponencial, construídos durante a graduação e durante um projeto de intervenção no referido componente. A questão de pesquisa foi: como organizações didáticas interferem na construção de conhecimentos/saberes de estagiários de Licenciatura em Matemática, sobre o conceito de função exponencial? Como metodologia, utilizou-se a engenharia didática de primeira geração. O quadro teórico foi composto pela Teoria das Situações Didáticas e pela Teoria Antropológica do Didático. A construção das situações-problema apoiou-se nas atividades selecionadas dos livros didáticos analisados e no estudo histórico-epistemológico do objeto matemático função exponencial. Os dados foram coletados durante as atividades de experimentação, realizadas nas aulas de Estágio Supervisionado. A análise dos dados permitiu identificar um conjunto de características positivas que evidenciam a influência da organização didática na construção e na consolidação dos saberes dos estudantes sobre a função exponencial, contribuindo para a formação desses futuros professores da Educação Básica.
\end{abstract}

Palavras-chave: Teoria das Situações Didáticas. Teoria Antropológica do Didático. Função Exponencial. Estágio Supervisionado.
Abstract: this work aims to show the main results of a master's research finished in 2015 . We examined the learning process of students at Mathematics graduation, from a state University in Bahia, during their studies at the discipline of supervised internship. The objective is to analyze how those subjects mobilized their mathematical knowledge about exponential functions, built while their formation and an intervention's project developed at the discipline

\footnotetext{
${ }^{1}$ Professora do quadro efetivo da Universidade do Estado da Bahia (UNEB). Doutoranda em Educação Matemática e Mestra em Educação Matemática pela Pontifícia Universidade Católica de São Paulo (PUC-SP). E-mail: ritalobof@gmail.com

${ }^{2}$ Doutorado em Mathematiques et Applications pela Universite de Rennes I (França). Professor assistente da PUC-SP. E-mail: saddoag@gmail.com
} 


\section{HORIZONTES - REVISTA DE EDUCAÇÃO}

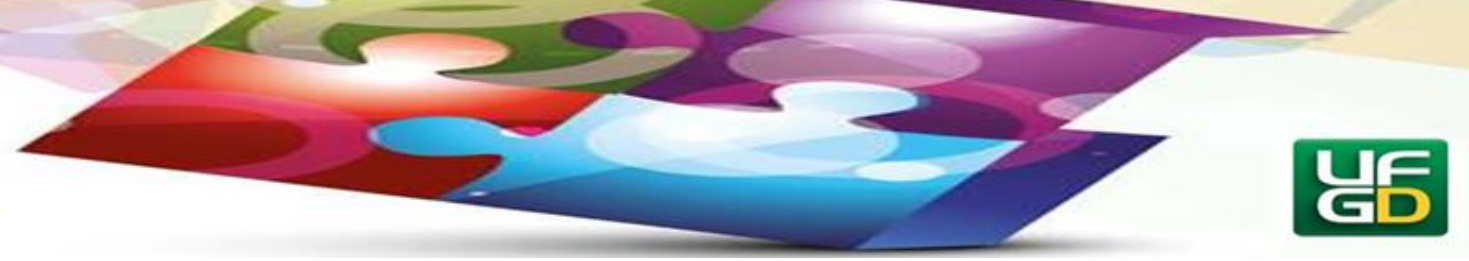

mentioned before. The main question at this research was: How didactic organizations interfere on building understandings/knowledge about exponential functions in a group of interns in a Mathematics graduation? The methodology used was the first-generation didactic engineering. The theoretical framework was composed by the theory of didactic situations and anthropologic theory of didactics. The conceive of problematic-situations was made from activities selected at textbooks investigated and historical-epistemological studies of the mathematical object itself. Data collected here during the experimentation activities at theoretical classes of supervised internship allowed us to realize a group of positive characteristics that evince the influences of the didactic organization at the building and setting of student's knowledges, both mathematical and didactical, about exponential functions, contributing to their formation as future teachers of basic education degree.

Keywords: Didactic Situations Theory. Anthropologic Theory of Didactics. Exponential Functions. Supervised Internship.

\section{Introdução}

No contexto da Educação Básica, as dificuldades dos alunos em aprender Matemática são constantemente relatadas por professores, pesquisadores e pelos próprios alunos. No campo de investigação em Educação Matemática, essas dificuldades têm ocupado um grande espaço de debate no meio científico, nos congressos, grupos de pesquisas e eventos da área. Pesquisas como as que trataram do ensino e da aprendizagem sobre funções, como Zuffi $(1999,2004)$ e Rossini (2006), relacionam diretamente as dificuldades dos alunos com a formação de seus professores e seus desafios para ensinar Matemática.

Ao analisar mais profundamente, a partir do Estágio Supervisionado, as dificuldades de estudantes e de professores da Educação Básica nos processos de aprendizagem e de ensino, respectivamente, foi possível perceber que parece existir um ciclo de perpetuação das dificuldades em aprender e ensinar Matemática: a dificuldade dos estudantes do Ensino Fundamental e Médio; dos graduandos da licenciatura em Matemática; dos professores do Ensino Médio, que já foram graduandos; e, na ponta deste trajeto cíclico, estão os professores formadores de outros professores, que podem ou não já ter ocupado esses diferentes papéis.

A licenciatura em Matemática, para a maioria dos acadêmicos, é o primeiro momento de formação acadêmica e profissional, que definimos como formação inicial do professor de Matemática. A formação continuada será caracterizada como aquela que ocorre após a formação inicial e no processo de atuação profissional do professor. Por outro lado, muitos desses sujeitos estudantes de licenciatura trazem consigo saberes anteriores à universidade, que 


\section{HORIZONTES - REVISTA DE EDUCAÇÃO}

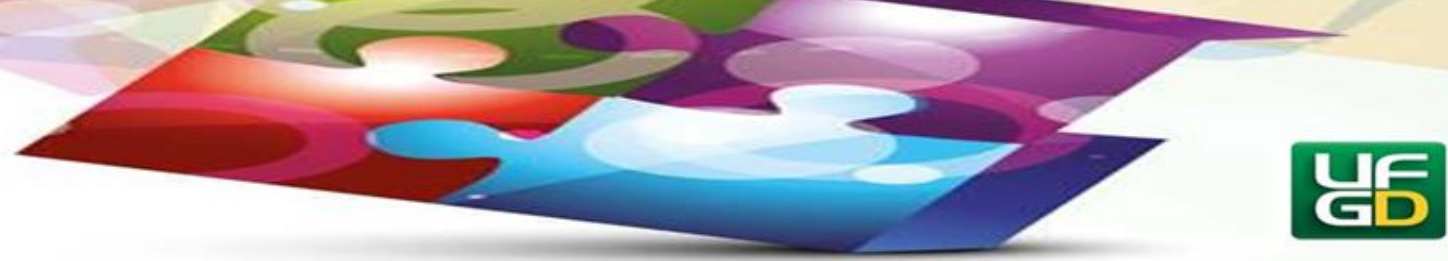

são adquiridos e produzidos durante esse processo de formação inicial, nesse sentido, tomam esses saberes como referência na construção de novos.

De acordo com Brito e Alves (2006), os professores (atuantes e futuros) produzem e adquirem seus saberes em sua formação anterior e durante a formação universitária, além disso, em sua prática docente. Segundo as autoras, esses fatores devem ser levados em consideração nas atividades de formação inicial ou continuada.

Poderíamos levantar diferentes aspectos da licenciatura em Matemática e realizar uma análise do processo de formação desses futuros professores, sob diversos enfoques, no entanto, delimitamos a discussão em duas categorias que julgamos fundamentais na formação do futuro professor.

A primeira é o aspecto curricular da formação. Neste caso, focamos a abordagem no âmbito do Estágio Supervisionado Curricular, também chamado, em alguns cursos de licenciatura, de Prática de Ensino. A outra é do ponto de vista dos saberes docentes necessários à prática do professor. Entendemos que essas duas categorias se entrelaçam no processo de formação, sobretudo, no desenvolvimento do Estágio Supervisionado.

Apesar de termos definido o estágio no âmbito curricular, quanto à categoria de discussão neste trabalho, importa situá-lo em uma posição que vai muito além de ser mais um componente do currículo da licenciatura. Pimenta (2004) afirma que o estágio ocupa uma posição de destaque no currículo e, consequentemente, na construção da identidade profissional dos acadêmicos (futuros professores).

Embora não tenhamos levantado todas as propostas de trabalho com Estágio Supervisionado nas Instituições de Ensino Superior (IES) da Bahia, nos cursos de licenciatura em Matemática, ao visitar o trabalho de Pires (2012), foi possível visualizar um panorama de como ocorrem os estágios nas IES baianas. Nessa perspectiva, identificamos, na pesquisa de Pires (2012), aspectos relevantes que apoiaram a pesquisa nesta proposta de intervenção no estágio.

A autora levanta dois questionamentos quanto à contribuição do estágio na licenciatura e na formação do futuro professor: “As Licenciaturas em Matemática continuam a repetir velhas práticas ou apresentam alguma (re) inovação na formação inicial do professor de Matemática?" (PIRES, 2012, p. 97). Além disso, outro questionamento é levantado pela autora, quanto às 


\section{HORIZONTES - REVISTA DE EDUCAÇÃO}

mudanças ocorridas na formação dos professores e incorporadas pelo Estágio Curricular Supervisionado.

De acordo com Pires (2012), houve poucos avanços nos cursos de licenciatura em Matemática com vistas à melhoria da qualidade e da aprendizagem de matemática nas escolas pesquisadas. As mudanças identificadas pela pesquisa, nas práticas dos professores regentes e nos trabalhos desenvolvidos pelos estagiários, pouco avançaram, deixando lacunas e não provocando mudanças no ritmo da escola. Segundo Pires (2012), o Estágio Supervisionado, atualmente, explicita a fragmentação do curso de licenciatura, ou seja, revela uma etapa de formação inicial desvinculada das demais etapas do curso.

Ressaltamos um aspecto, também sinalizado pela autora, que precisa ser repensado: a competência básica do professor e as mudanças pedagógicas produzidas em sala de aula, as quais devem perpassar o domínio do conteúdo específico de Matemática. Somente a partir dele, será possível construir e produzir ações educativas competentes.

A partir dos dados da pesquisa de Pires (2012), acreditamos que as propostas de estágio, desenvolvidas até este momento na Bahia, não têm evidências de ter proporcionado uma verdadeira articulação entre o saber matemático e o saber pedagógico. O Estágio Supervisionado, então, deveria privilegiar uma discussão do conteúdo matemático articulada com a didática da Matemática, algo que tem por foco uma reflexão sobre os processos de ensino e de aprendizagem, nos quais estão inseridos os estagiários, ora intervindo como professores, ora como estudantes. Além disso, as reflexões sobre a prática de sala de aula na prática do estágio são fundamentais na construção da identidade do futuro docente, evidentemente, envolvendo os professores das escolas com os projetos de estágio.

O levantamento bibliográfico realizado em nosso estudo identificou a existência de um número maior de pesquisas sobre o processo de aprendizagem dos estudantes, que sobre professores e sua formação. Esse aspecto denota a necessidade de pesquisas de campo voltadas para a formação inicial de professores da Educação Básica.

Das pesquisas já realizadas com professores, destacamos aquelas relacionadas ao estudo de funções, como a de Rossini (2006) e de Zuffi (1999, 2004). Tais pesquisas apontaram as fragilidades na formação do professor de Matemática. Para Zuffi (2004), a maneira exclusivamente formal como o conceito de função é trabalhado com os estudantes não é suficiente para que os futuros professores possam ter uma visão conceitual ampliada. Esse 


\section{MORIZONTES - REVISTA DE EDUCAÇÃO}

contexto não é diferente em relação ao ensino da função exponencial, pois percebemos que nossos estudantes de licenciatura, na fase de Estágio Supervisionado, tendem a reproduzir as fragilidades, os erros e equívocos conceituais na sua prática de ensino (em turmas de Ensino Médio) do estágio.

Por outro lado, não é apenas o domínio conceitual matemático, embora este seja fundamental, que poderá garantir o sucesso da prática de ensino na Educação Básica. Para desenvolver uma proposta voltada para o ensino de função exponencial, os sujeitos que ensinam precisam de domínio de certos saberes inerentes à prática docente e que devem ser trabalhados durante a licenciatura, inclusive no Estágio Supervisionado.

Tardif (2012, p. 36) define os saberes docentes a partir da relação entre o professor e o saber, o autor afirma que a relação entre professores e saberes não está reduzida a uma mera transmissão de conhecimentos, ao contrário, sua prática integra diferentes saberes, formada por um amálgama de saberes da formação profissional e daqueles "disciplinares, curriculares e experenciais".

Em nosso trabalho, quando usamos a expressão "conhecimento/saber sobre a função exponencial", estamos nos referindo ao conhecimento matemático aliado ao conhecimento didático (teórico) sobre a função exponencial, que está mais de acordo com o que Tardif (2012, p. 38) chama de saberes disciplinares: “[...] estes saberes integram-se igualmente à prática docente por meio da formação (inicial e continuada) dos professores nas diversas disciplinas oferecidas pela universidade". De uma forma geral, o conhecimento didático a que nos referimos é o da didática da Matemática que deve se aliar à atividade prática do professor (ou futuro professor), em uma proposta de ensino de qualquer saber matemático, seja no estágio ou na prática.

Em relação ao estágio, Pimenta e Lima (2011) afirmam que: “O estágio não é uma atividade prática, mas teórica instrumentalizada da práxis docente, entendida como atividade de transformação da realidade. Nesse sentido, o estágio curricular é atividade teórica de conhecimento, fundamentação, diálogo e intervenção na realidade, esta sim, objeto da práxis" (PIMENTA; LIMA, 2011, p. 45).

Apoiados em Tardif (2012) e Pimenta e Lima (2011), defendemos que esses saberes docentes (saberes disciplinares), a que nos referimos anteriormente, devem compor o repertório dos estagiários, formandos dos cursos de licenciatura. Mas, de acordo com Tardif (2012), certo 


\section{HORIZONTES - REVISTA DE EDUCAÇÃO}

saberes inerentes à docência só serão desenvolvidos pelos sujeitos, na atividade profissional docente, seja na efetiva regência de sala de aula, nas atividades pedagógicas de planejamento da escola, no envolvimento com os projetos escolares, dentre outras atividades.

Essas reflexões apresentadas anteriormente foram um marco para propormos uma experiência de ensino e aprendizagem diferente das propostas de Estágio Supervisionado tradicionais, a qual poderia trazer um impacto positivo ao processo de aprendizagem dos sujeitos envolvidos e elucidar novas questões quanto à formação do professor de Matemática da Educação Básica.

A partir do estudo realizado sobre a licenciatura e a formação inicial docente, percebemos que a proposta de estágio deveria ser pautada em objetivos didáticos que pudessem promover impacto positivo na formação desses futuros professores, incluindo os materiais didáticos próprios da prática docente, de professores do Ensino Médio. Nesse sentido, delineamos os objetivos da pesquisa, tendo como metodologia a engenharia didática segundo de Artigue (1988).

O objetivo geral foi analisar as organizações praxeológicas construídas pelos estagiários do curso de licenciatura em Matemática, sobre a função exponencial, durante a realização das atividades de experimentação. Definimos quatro objetivos específicos:

- Analisar as organizações matemáticas e didáticas propostas pelos autores dos livros didáticos escolhidos, mais especificamente, identificar e analisar os tipos de tarefa (e técnicas relacionadas com esses tipos de tarefas) no intuito de fazer inferências sobre o provável conhecimento/saber que seria aprendido pelo aluno sujeitado à prática docente apoiada nesses livros;

- Construir, analisar e experimentar uma sequência de atividades no intuito de identificar o significado da função exponencial construído por estagiários de Licenciatura em Matemática;

- Analisar como essa sequência pode contribuir (ou contribuiu) para consolidação de saberes referentes à função exponencial e seu campo conceitual por parte dos sujeitos de pesquisa;

- Promover um ambiente de engajamento espontâneo dos sujeitos com a perspectiva de melhoria na sua formação acadêmica enquanto futuro professor da Educação Básica; 


\section{HORIZONTES - REVISTA DE EDUCAÇÃO}

e-ISSN: 2318-1540

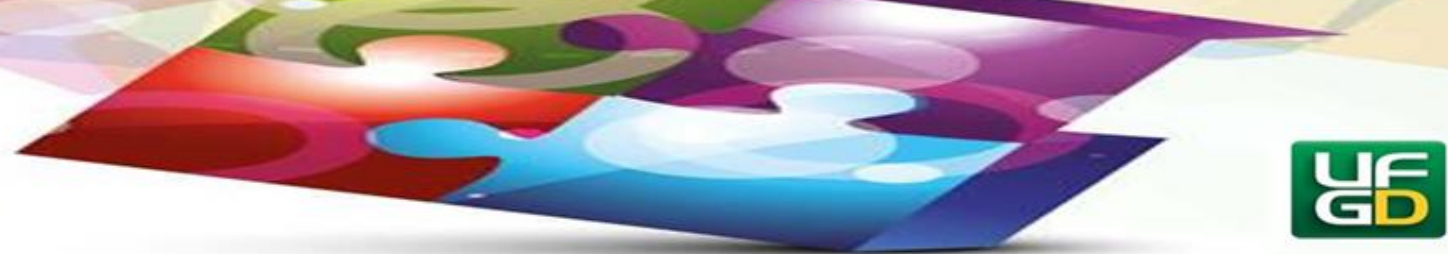

- Promover uma articulação entre o trabalho didático da escola básica e o trabalho acadêmico realizado na universidade, a partir da experiência de Estágio Supervisionado;

- Contribuir para melhoria da qualidade da Educação Básica por meio da formação inicial de seus futuros professores.

A partir dos objetivos bem delineados, desenvolvemos a pesquisa seguindo os pressupostos da engenharia didática de Artigue (1988).

\section{Desenvolvimento da pesquisa}

Na Engenharia Didática de Artigue (1988), encontramos os pressupostos necessários para o desenvolvimento da investigação, no intuito de utilizar uma metodologia que pudesse viabilizar a construção de situações de aprendizagem a ser aplicadas em uma turma de Estágio Supervisionado. De acordo com Almouloud (2007, p. 169),

[...] o objetivo de uma pesquisa é confirmar ou refutar contribuições teóricas a partir de uma argumentação que esse apoia em uma experimentação. A problemática refere-se aos artigos e obras atestados ou trabalhos que tratam do assunto em um processo de validação-refutação, propondo as etapas da pesquisa e da experimentação, além de definir como esse plano corresponde aos objetivos.

A Engenharia Didática se caracteriza por um esquema experimental, que, além das realizações em sala de aula, perpassa a "construção, realização e análise de sessões de ensino" (ALMOULOUD, 2007, p. 171). Além disso, a comparação entre a análise a priori e análise a posteriori permite o processo de validação, sem necessariamente ter de se aplicar algum tipo de pré-teste, pois a validação é interna. Nessa perspectiva, a pesquisa foi desenvolvida basicamente em cinco etapas: pesquisa bibliográfica a respeito dos trabalhos já realizados com estagiários da Licenciatura em Matemática, com função exponencial e formação de professores; análise de livros didáticos do Ensino Médio, com base em Chevallard (1999); estruturação e organização de situações de experimentação; realização de sessões de ensino (experimentação), tendo como produto de cada sessão as produções escritas e os registros orais dos estudantes; avaliação dos resultados obtidos.

A partir dos resultados já apontados sobre a fragilidade da formação inicial de professores, inclusive sobre a função exponencial, organizamos a engenharia conforme os 


\section{MORIZONTES - REVISTA DE EDUCAÇÃO}

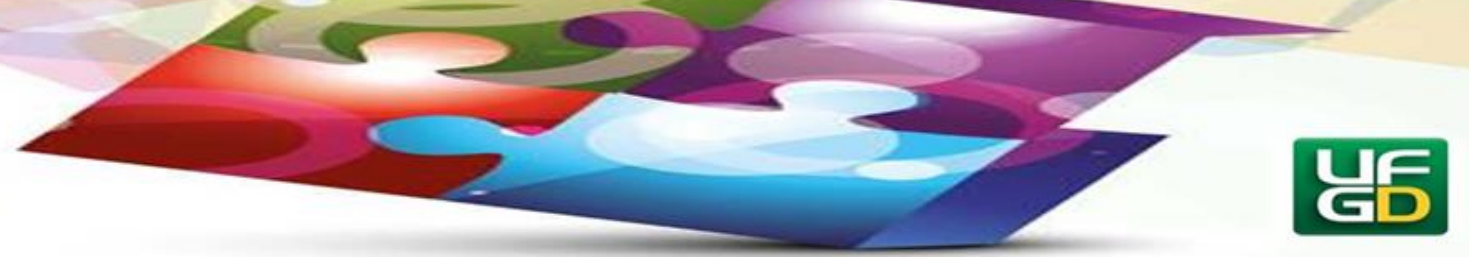

pressupostos de Artigue (1988): análises prévias, construção das situações e análise a priori, experimentação, análise a posteriori e validação. Realizamos, na etapa das análises prévias, um levantamento histórico-epistemológico do objeto matemático função exponencial. Nesta etapa, buscamos apoio nas pesquisas já realizadas sobre função e função exponencial.

Ainda na etapa de análises prévias, realizamos um levantamento das pesquisas recentes acerca do tema função exponencial. Nesta etapa, também definimos nossa questão de pesquisa, a problemática e as hipóteses de trabalho. Entendemos que a etapa de análises prévias não se encerra até o fim da pesquisa, pois novas contribuições podem surgir no decorrer do percurso.

Na sequência, organizamos e estruturamos situações e experimentação, por meio de uma sequência didática de atividades sobre os objetos matemáticos inspiradas em atividades de livros didáticos do Ensino Médio brasileiro. Todas as situações de aprendizagem foram estruturadas com base na Teoria das Situações Didática (TSD), tendo como base Brousseau (1996, 2008) e Almouloud (2007).

As sessões de ensino foram desenvolvidas em duas etapas: na primeira, os estudantes deveriam trabalhar com atividades que envolvessem os conceitos matemáticos relativos à função afim e a função exponencial no sentido de (re) construir saberes matemáticos referentes a estes objetos; na segunda etapa, as situações propostas deveriam permitir aos estudantes elaborar uma sequência de ensino que pudesse ser desenvolvida com uma turma de Ensino Médio.

Com relação aos conceitos matemáticos construídos pelos sujeitos, interessava-nos identificar o trabalho cognitivo realizado por eles durante esse processo de aprendizagem, na elaboração de organizações matemáticas. Nesse sentido, a análise desse processo se apoia nas construções matemáticas realizadas pelos sujeitos evidenciadas nas atividades, por meio das técnicas utilizadas nas soluções das tarefas propostas.

Para analisar a construção dos conceitos por parte dos sujeitos, consideramos as condutas observadas, a partir dos registros escritos e das expressões orais. Neste caso, a TSD norteia a construção, a análise e o processo de experimentação de situações que, a priori, conduzirão a um processo de modificações dos comportamentos dos estudantes, característico da aquisição de novos conhecimentos (BROUSSEAU, 2008).

Partindo do pressuposto de que a TSD nos fornece um percurso que favorece o processo de aprendizagem, em nossas análises, o principal objetivo foi perceber se houve aprendizagem 


\section{HORIZONTES - REVISTA DE EDUCAÇÃO}

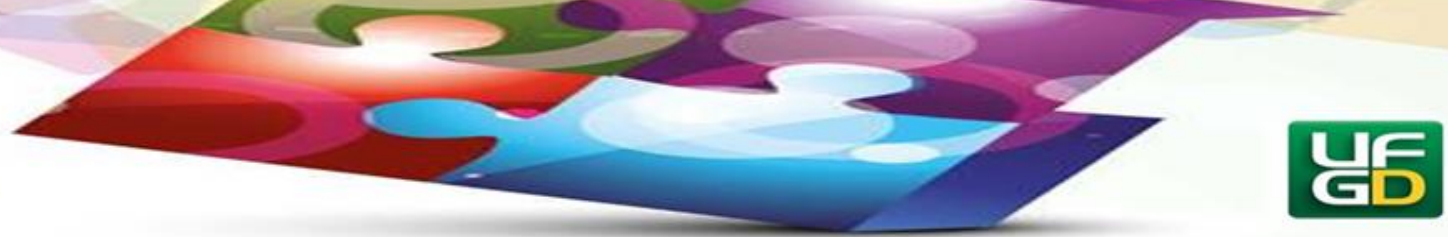

por parte do sujeito e quais elementos conceituais foram agregados à estrutura cognitiva, frente aos conceitos anteriormente construídos pelos sujeitos.

As sessões de ensino, organizadas segundo o quadro 1, desenvolveram-se em cinco momentos, cada um com 3 (três) horas/aula. Nessas sessões, os estagiários (futuros professores) foram orientados sobre os procedimentos que seriam desenvolvidos. Eles iriam receber as atividades, discutir com o colega da dupla e, em seguida, apresentar para os demais presentes na turma. Ao final, a professora (pesquisadora) levantaria a discussão sobre o que cada grupo havia apresentado.

Quadro 1: Procedimentos Gerais das Sessões de Ensino

\begin{tabular}{|c|c|c|}
\hline $\mathbf{E X}$ & $\begin{array}{r}\text { DESI } \\
\text { SES }\end{array}$ & \\
\hline 0100 (2) & \multirow{4}{*}{$\begin{array}{l}\text { - Resolução de situações-problema } \\
\text { em duplas, com a vigilância } \\
\text { epistemológica da professora; } \\
\text { - Socialização e discussão (entre as } \\
\text { duplas) das estratégias de } \\
\text { resolução e dos resultados } \\
\text { encontra dos em cada tarefa, bem } \\
\text { como as justificativas } \\
\text { matemáticas para cada solução; } \\
\text { - Institucionalização de cada } \\
\text { atividade, por parte da professora; } \\
\text { - Elaboração de uma sequência de } \\
\text { ensino para estudantes do ensino } \\
\text { médio, a partir de uma situação- } \\
\text { problema de sala de aula } \\
\text { apresentada pela professora } \\
\text { (pesquisadora); } \\
\text { - Desenvolvimento das Dialéticas } \\
\text { adidáticas (ação, formulação, } \\
\text { validação); inaça } \\
\text { - Dialética de institucionalização; } \\
\text { - Elaboração de uma sequência de } \\
\text { ensino para turmas do ensino } \\
\text { médio; }\end{array}$} & \multirow{4}{*}{$\begin{array}{l}\text { - Uso de material } \\
\text { impresso /atividades; } \\
\text { - Laboratório e } \\
\text { informática com os } \\
\text { softwares disponíveis: } \\
\text { Excel e Geogebra; } \\
\text { - Internet com acesso a } \\
\text { um ambiente virtual } \\
\text { para registrar as } \\
\text { produções digitais dos } \\
\text { estudantes; } \\
\text { - Gravadores de voz, } \\
\text { para registrar o } \\
\text { trabalho oral das } \\
\text { duplas; } \\
\text { - Quadro, piloto, } \\
\text { apagador, Datashow, } \\
\text { papel lápis e borracha; } \\
\text { - Livros didáticos }\end{array}$} \\
\hline$=\left(1+\frac{1}{x}\right)^{x}$. Construir & & \\
\hline 年 & & \\
\hline $\mathrm{C}+\mathrm{C}$ & & \\
\hline
\end{tabular}

\footnotetext{
3 Segundo Duval (1999), um registro de representação é um sistema semiótico que tem funções cognitivas fundamentais no funcionamento cognitivo consciente do sujeito. Nessa perspectiva, os registros se diferenciam dos códigos, pois estes são mais limitados que os registros. A diferença entre registros e códigos se pauta em dois níveis do funcionamento cognitivo: um consciente e outro inconsciente, todo conhecimento implica necessariamente a mobilização desses dois níveis.
} 


\section{HORIZONTES - REVISTA DE EDUCACÃOO}

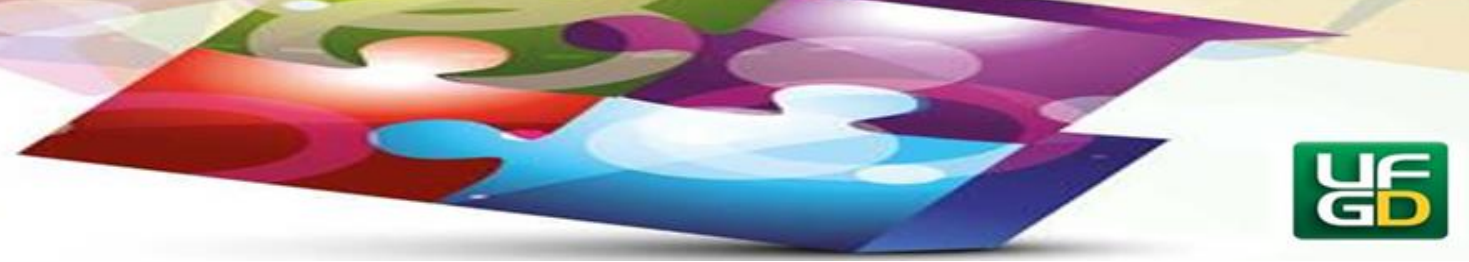

\begin{tabular}{|l|c|c|}
\hline $\begin{array}{l}\text { Sessão 05: Os estudantes deveriam } \\
\text { organizar uma sequência didática para uma }\end{array}$ & $\begin{array}{c}\text { C Construção de tabelas usando } \\
\text { Excel }\end{array}$ \\
turma de $1^{\circ}$ do ensino médio, sobre função & • Construção e analise de gráficos \\
$\begin{array}{l}\text { exponencial, levado em conta os conceitos } \\
\text { construídos na formação. (atividade 09) }\end{array}$ & $\begin{array}{l}\text { usando o recurso computacional } \\
\text { Geogebra. }\end{array}$ & \\
\hline
\end{tabular}

Fonte: Adaptado de Freitas (2015).

Na construção das situações de experimentação, construímos uma sequência didática composta por situações-problema, em que identificamos os objetivos, as variáveis (macro e micro) didáticas. Após a construção das situações de experimentação, procedemos a uma "análise a priori” da sequência didática. Nesta etapa, o nosso principal objetivo foi tentar prever as condutas dos sujeitos, os estagiários da licenciatura, frente à proposta das atividades.

As situações de experimentação se apoiaram nas atividades constantes e não constantes nos livros didáticos, nas pesquisas consultadas e em novas situações previamente identificadas, no diagnóstico, como ponto de dificuldade dos sujeitos.

Ao se confrontarem com as situações problemas, a priori, os sujeitos deveriam desenvolver um trabalho de investigação frente ao saber em jogo, organizar técnicas mais ou menos validas e aceitas dentro do contexto das situações adidáticas, nas dialéticas de ação, formulação e validação. O objetivo final é a construção e/ou a ressignificação do saber em jogo.

Ressaltamos que, na primeira sessão (ver quadro 1), visamos a desenvolver atividades em torno dos conceitos gerais de função e das funções linear e afim, com o intuito de adaptar os sujeitos à proposta da formação, bem como retomar os conhecimentos prévios para o trabalho com a função exponencial nas demais sessões.

De uma forma geral e resumida, o quadro 1 apresenta o trabalho realizado em cada sessão de ensino. A seguir, tomaremos a primeira sessão para ilustrar mais detalhadamente como ocorreu, em cada etapa, o desenvolvimento da engenharia didática.

\section{Estruturação e análises}

Conforme elucidamos anteriormente, vamos ilustrar, por meio da primeira sessão, como foram estruturadas as análises de cada sessão de ensino, os resultados esperados a priori e o que foi observado após a experimentação, bem como as conclusões parciais. 


\section{HORIZONTES - REVISTA DE EDUCAÇÃO}

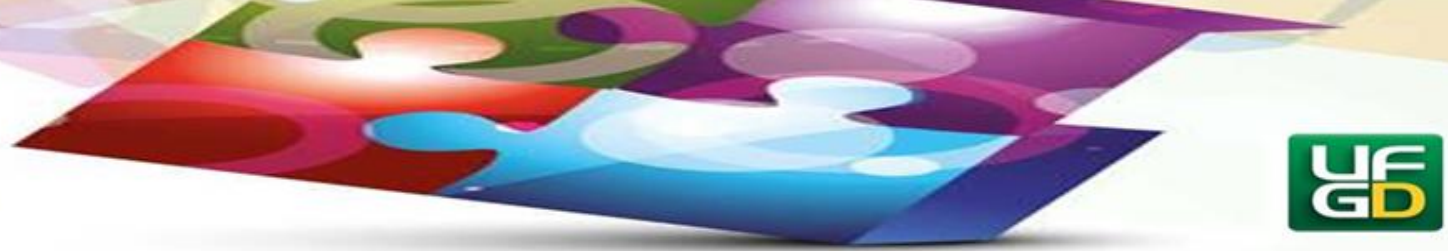

Na primeira sessão de ensino, explicamos aos estudantes a dinâmica das atividades de pesquisa e que o principal objetivo da proposta seria contribuir com a formação profissional e acadêmica deles.

A partir das análises prévias, em especial do estudo do objeto matemático, foi possível perceber a necessidade de retomar alguns conceitos prévios para o estudo da função exponencial. Este fato motivou a escolha das atividades 01 e 02, nas quais trabalhamos inicialmente com alguns conceitos prévios, indispensáveis ao estudo do conceito de função exponencial. De forma geral, os conceitos de função, de função linear e função afim podem auxiliar na manipulação e no tratamento de função exponencial.

Nas atividades propostas, diferentes estratégias de cálculo poderiam ser mobilizadas, ativando os conceitos matemáticos auxiliares para o tratamento de funções e organizadores da estrutura matemática fundamental, do repertório cognitivo do estudante.

Um de nossos objetivos foi que o estudante pudesse, ao final dessa sessão, perceber diferentes funções, relembrar conceitos, para, em um segundo momento, mobilizá-los em situações envolvendo o conceito de função exponencial. Escolhemos as funções afim e linear no contexto das atividades 1 e 2 .

Em um experimento anterior, detectamos que os estudantes confundiam a função exponencial com a função linear, inclusive suas representações gráficas. Eles confundiram a expressão $a x \operatorname{com} a^{x}$. Nesse sentido, explicitar a função linear, inclusive como caso particular da função afim, em segundo momento, permitiu-lhes comparar esses modelos e entender a diferença entre crescimento exponencial e crescimento linear. Por esta razão, incluímos, na sequência didática, as duas atividades sobre função afim e linear.

Escolhemos trabalhar com a lei de formação da função afim definida por $f(x)=a x+$ $b$, com a e $\mathrm{b}$, número reais $(f: \mathbb{R} \rightarrow \mathbb{R})$. Quando $\mathrm{b}=0$, a função é chamada de função linear, e definida por: $f(x)=a x$. É importante trabalhar com conceitos prévios no sentido de fornecer aos estudantes elementos que os auxiliem na construção do novo conhecimento. Nesse contexto, algumas competências relacionadas ao conceito de função - tais como construção e interpretação de gráficos, manipulação de variáveis dependentes, interpretação de texto em língua natural - são importantes.

A análise a priori realizada envolve uma análise matemática e uma análise didática. $\mathrm{Na}$ análise matemática, identificamos as metodologias, as estratégias matemáticas de resolução 


\section{HORIZONTES - REVISTA DE EDUCAÇÃO}

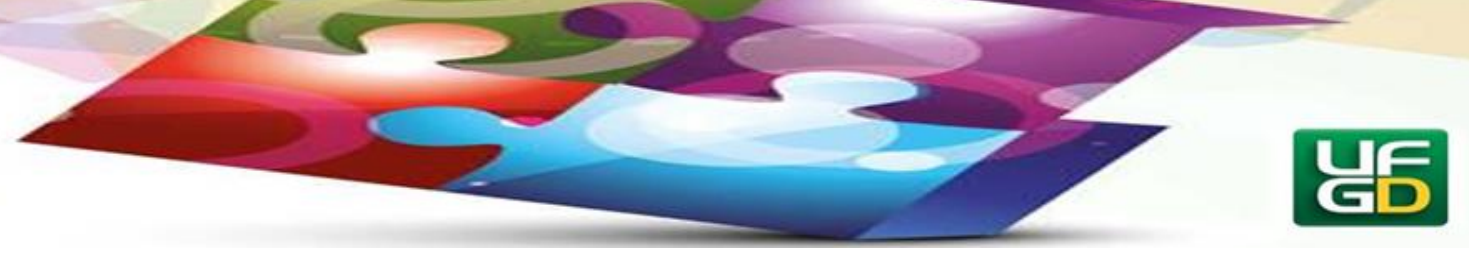

de cada situação-problema e evidenciamos os saberes matemáticos envolvidos. Com relação à análise didática, apresentamos os possíveis comportamentos dos sujeitos, suas dificuldades e as variáveis didáticas que são necessárias para o estudo, a partir da mobilização de conceitos envolvidos nas situações. Consideramos importante perceber como os sujeitos organizam o saber pela observação de suas representações e análise de seu discurso.

Estruturamos a análise didática a partir da discussão das diferentes dialéticas (ação, formulação, validação) e da posterior institucionalização.

$\mathrm{Na}$ atividade1, composta de três situações-problema, de acordo com o quadro 2, temse por objetivo estudar o conceito geral de função afim, definida por $f(x)=a x+$ $b$, com $a, b \in \mathbb{R}$ e $a \neq 0$. Além disso, perceber que, se $b=0$, a função será definida por $f(x)=a x$, uma função linear. A partir da representação gráfica da função afim e da função linear, o estudante deverá perceber diferenças no comportamento dessas funções e estabelecer relações entre a representação gráfica e algébrica, tendo como base os coeficientes reais a e b, associando-os ainda com os pontos de coordenadas $(0, y)$ e $(x, 0)$, intersecções dos gráficos com os eixos coordenados.

\section{Quadro 2: Organização da Atividade 1}

\section{ATIVIDADE 1}

Situação-problema 01 - Um dos insetos mais destrutivos é o gafanhoto-do-deserto. Esse inseto é capaz de comer cerca de 1,6 gramas de folhas por dia. Considerando que algumas nuvens de gafanhotos podem conter cerca de 50 milhões de indivíduos, a devastação pode alcançar grandes proporções. Quantas toneladas de folhas uma nuvem de gafanhotos pode comer em um único dia?

(A) Podemos estabelecer um modelo matemático para essa situação-problema? Justifique. Qual? (B) O que podemos afirmar sobre esse modelo? É possível representá-lo graficamente? (SOUZA, 2010, p.84, adaptação nossa).

Situação-problema 02 - A receita mensal de vendas de uma empresa está relacionada com os gastos mensais com propaganda. Quando a empresa gasta $\mathrm{R} \$ 10.000,00$ por mês com propaganda, sua receita naquele mês é de $\mathrm{R} \$ 80.000,00$. Se o gasto mensal com propaganda for o dobro daquele, a receita mensal cresce $50 \%$ em relação àquela.

(A) Qual a receita mensal, se o gasto com propaganda for R $\$ 30.000,00$ ? (B) Podemos estabelecer um modelo matemático para essa situação problema? Justifique. Qual? (C). O que podemos afirmar sobre esse modelo? É possível representá-lo graficamente?

Situação-problema 03 - Carlos trabalha como DJ e cobra uma taxa de $\mathrm{R} \$ 100,00$, mais $\mathrm{R} \$ 20,00$ por hora, para animar uma festa. Daniel, na mesma atividade, cobra uma taxa de R\$55,00, mais R\$35,00 por hora. (RIBEIRO, 2012, p.95, adaptação nossa).

(A) Qual o tempo máximo de duração de uma festa, para que a contratação de Daniel não fique mais cara que a de Carlos? (B) Agora faça uma discussão com seu colega relacionando os pontos em comum das situações propostas, fazendo comparações, justificando suas conclusões na linguagem materna e matemática

Fonte: Freitas (2015, p. 81). 


\section{HORIZONTES - REVISTA DE EDUCAÇÃO}

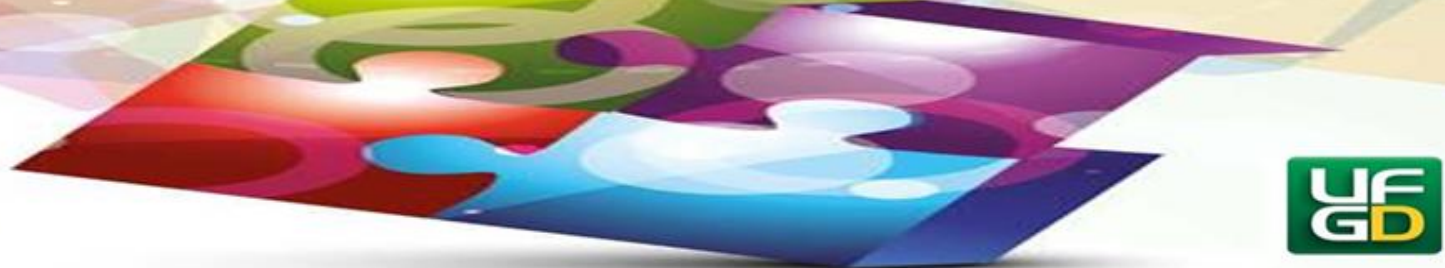

A análise matemática consiste exatamente na resolução das atividades. Supondo que priori pode ser desenvolvida, pode conter diferentes técnicas de resolução. A seguir, apresentamos como foram analisadas matematicamente as situações-problema.

$\mathrm{Na}$ letra (A), sobre a situação problema 1, inicialmente, deve-se estabelecer a relação de dependência entre as grandezas: quantidade (massa) de folhas destruídas (m) pela quantidade de gafanhotos (q). Nesse caso, o modelo matemático é o da função linear definida por: $\mathrm{m}(\mathrm{q})=$ 1,6 q. Portanto uma nuvem de gafanhotos será: $\mathrm{m}(50.000 .000)=1,6 \times 50.000 .000=80.000 .000$ g. Transformando para toneladas, (t) $80.000 .000 \mathrm{~g}=80.000 \mathrm{~kg}$ (quilogramas) $=80 \mathrm{t}, \mathrm{m}$ $(50.000 .000)=80 \mathrm{t}$. Outra solução que os sujeitos podem dar para a letra (A) é efetuar a multiplicação direta $50.000 .000 \times 1,6=80.000 .000 \mathrm{~g}=80.000 \mathrm{~kg}=80 \mathrm{t}$, sem estabelecer uma escrita formal representativa de função. Pode-se afirmar que o modelo matemático é sempre de valores múltiplos de 1,6.

Figura 1: Gráfico da situação-problema 1 - letra B

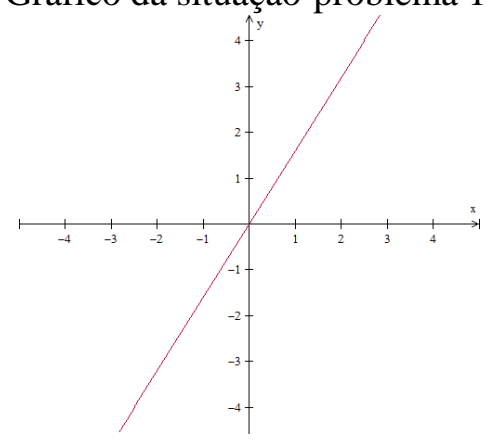

Fonte: Freitas (2015, p. 82).

$\mathrm{Na}$ letra (B), o modelo corresponde ao de uma função linear $\mathrm{f}$ definida por $f(x)=$ a. $x$, com $a \neq o$, nesse caso, $a=1,6$. Podemos representar graficamente (figura 8) por uma reta que passa pela intersecção dos eixos coordenados.

$\mathrm{Na}$ situação-problema 2, a estratégia inicial que pode ser utilizada no item A pelo estudante é estabelecer as relações entre as grandezas receita e custos com propaganda, a partir dos dados fornecidos pelo problema. Assim, temos: $\mathrm{R}(10.000)=80.000$. Considerando $\mathrm{R}=$ receita e $\mathrm{p}=$ custo com propaganda:

$$
\mathrm{R}(20.000)=80.000+50 \% .80 .000 \Rightarrow \mathrm{R}(20.000)=80.000+\frac{1}{2} 80.000=120.000 .
$$




\section{HORIZONTES - REVISTA DE EDUCAÇÃO}

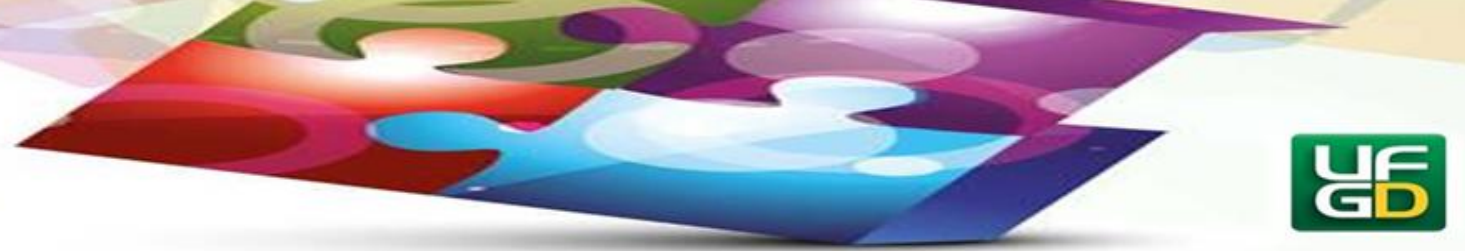

Nesse caso, pode-se estabelecer uma relação de dependência entre R e p, típica de uma função, além da existência de uma receita fixa e de outra variável. O estudante pode tentar generalizar o problema com a expressão da função afim, para, depois, encontrar a receita quando o gasto com propaganda for 30.000 .

Tomando as relações de dependência entre os valores de $\mathrm{R}$ e p, a partir da lei de formação da função afim, definida como $R(p)=a \cdot p+b$, temos que: $R(p)=10.000 \cdot a+$ $b=80.000$. Ou seja, quando o gasto (p) é 10.000 , a receita (R) é igual a 80.000 . Por outro lado, quando o gasto dobra, passa para 20.000, a receita aumenta em 50\%, $\operatorname{logo} R(p)=$ 20.000 $a+b=120.000$. A partir dessas conclusões, pode-se montar um sistema e calcular os valores de a e b. $\left\{\begin{array}{c}10.000 a+b=80.000(I) \\ 20.000 a+b=120.000(I I)\end{array}\right.$. Resolvendo o sistema pelo método da adição, temos: (II)-(I) $=10.000 a=40.000 \Rightarrow a=\frac{40.000}{10.00} \therefore \boldsymbol{a}=\mathbf{4}$.

Substituindo o valor de $a$ na equação (I), temos: $10.000 .4+b=80.000 \Rightarrow b=$ $80.000-40.000 \therefore \boldsymbol{b}=\mathbf{4 0 . 0 0 0}$. Logo, substituindo os valores de a e b na expressão da função definida por $R(p)=a \cdot p+b$, temos: $R(p)=4 x+40.000$, e, consequentemente, se $p=30.000$, então $R(30.000)=4.30 .000+40.000=160.000$.

Outro método de resolução que pode ser realizado é utilizar as relações entre as grandezas e representá-las diretamente como pares ordenados. A partir da identificação da dependência das grandezas e associação de cada par de valores $\left(\mathrm{x}_{1}, \mathrm{y}_{1}\right)$ e ( $\left.\mathrm{x}_{2}, \mathrm{y}_{2}\right)$, obtém-se: ( $\mathrm{x}_{1}$, $\left.\mathrm{y}_{1}\right)=(10.000 ; 80.000)$ e $\left(\mathrm{x}_{2}, \mathrm{y}_{2}\right)=(20.000 ; 120.000)$. Estabelecendo como lei de formação da relação existente entre as grandezas receita $(R)$ e custo de propaganda (p), a função afim $f$, definida por $f(x)=a x+b$, monta-se um sistema de equações e, a partir de então, conforme a resolução anterior, procede-se o cálculo do valor de $\mathrm{R}(\mathrm{p})$ quando p é igual a 30.000.

Letra (B e C): a resposta para a pergunta é sim, e o modelo é o de função afim, neste caso, definida por $R(p)=4 p+40.000$, outras letras poderão ser utilizadas em substituição a R e p. A representação gráfica pode sim ser construída no plano cartesiano de eixos coordenados $\mathrm{x}$ (custo de propaganda p) e y (receita mensal R). Para construção do gráfico, os estudantes poderão construir uma tabela de valores para x e y, ou apenas encontrar os pontos $(x, 0)$ e $(0$, y) e construir a reta que passa por esses dois pontos:

$(-10.000,0)$ e $(0,40.000)$. 


\section{HORIZONTES - REVISTA DE EDUCAÇÃO}

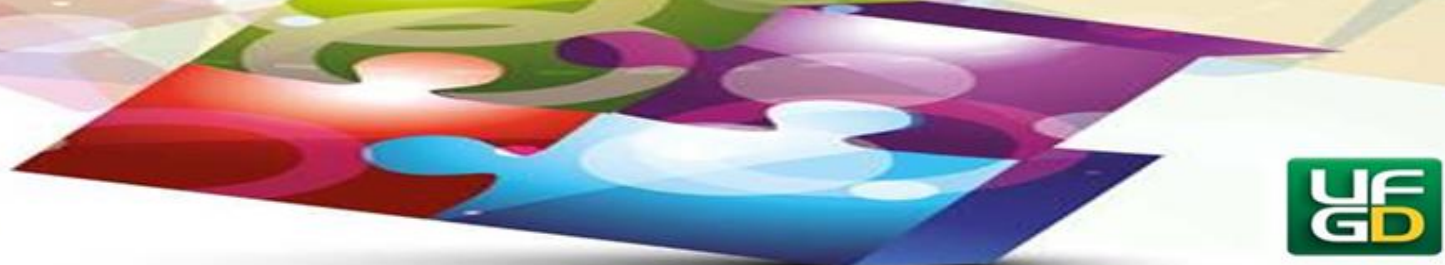

Nota-se que a razão de proporção entre os valores de a e b é muito grande, necessitando fazer o gráfico em uma escala de 1/10.000, conforme a seguir.

Figura 2: Gráfico da situação-problema 2 - letra C

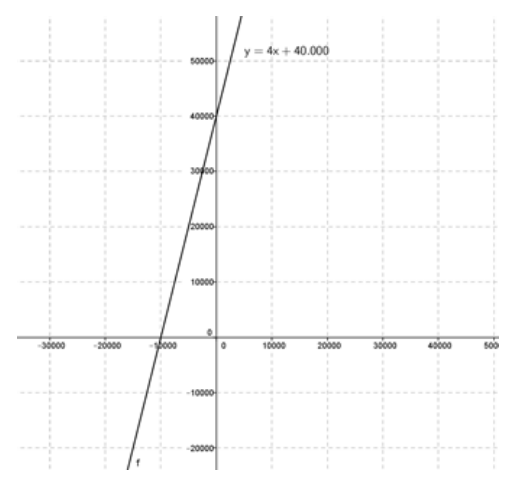

Fonte: Freitas (2015, p. 84).

Na situação problema 3, no item (A), para estabelecer uma comparação entre o trabalho de Daniel e o de Carlos, temos de definir as equações que representam as duas propostas. A partir da leitura, é possível escrever o modelo das equações referentes a Carlos e Daniel em função do tempo da festa, respectivamente: $C(t)=20 t+100$ e $D(t)=35 t+55$. A leitura permite concluir que o valor de $\mathrm{t}$ buscado é aquele que estabelece uma relação de ordem $\mathrm{D}(\mathrm{t}) \leq \mathrm{C}(\mathrm{t})$ então: $35 t+55 \leq 20 t+100$. Resolvendo a inequação: $35 t-20 t \leq 100-55 \Rightarrow 15 t \leq 45 \Rightarrow t \leq$ $\frac{45}{15} \Rightarrow \mathrm{t} \leq 3$.

O tempo máximo de duração da festa deve ser de $3 \mathrm{~h}$, para que a contratação de Daniel não fique mais cara que a de Carlos. Ou seja, a contratação de Daniel deve ser o mesmo valor ou menor que a de Carlos. No item (B), uma possibilidade de discussão da tarefa é perceber que, quando a duração da festa for igual a $3 \mathrm{~h}(\mathrm{t}=3)$, a contratação de Daniel terá o mesmo valor que a de Carlos. Isto é facilmente verificado pela substituição de $\mathrm{t}=3$ nas duas funções: $\mathrm{C}(3)=20.3+100=160$ e $\mathrm{D}(3)=35.3+55=160$.

$\mathrm{Na}$ atividade 01, o conjunto das situações-problema proposto apresenta uma consistência para ressignificar o conceito de dependência de variável, central para o estudo de funções. A retomada da lei de associação da função afim evidencia a função linear como caso particular, além de possibilitar uma visualização de sua representação gráfica. O objetivo é 


\section{HORIZONTES - REVISTA DE EDUCAÇÃO}

e-ISSN: 2318-1540

justamente desfazer a confusão causada por estudantes com o modelo exponencial de crescimento. A análise didática fundamentada no princípios da TSD, segundo Brousseau (1996, apud ALMOULOUD, 2007).

Em situação de ação, os sujeitos deverão realizar a leitura das situações-problema em linguagem natural, buscando relacioná-las com a linguagem matemática, a partir da mobilização de esquemas cognitivos relacionados à leitura em linguagem natural. Nesse percurso, o aluno poderá identificar as grandezas envolvidas e suas relações: quantidade de folhas por quantidade de gafanhotos, receita por quantidade de propaganda e valor pago por horas de serviço. A forma como vão representar matematicamente as grandezas identificadas nas situações-problema pode variar.

Numa situação de formulação, os estudantes deverão utilizar a noção de dependências de grandezas, buscando identificar modelos matemáticos coerentes com a lei geral de formação de uma função linear e função afim definida por $\mathrm{f}(\mathrm{x})=\mathrm{ax}+\mathrm{b}$. As estratégias de cálculo utilizadas podem ser caracterizadas pelas técnicas de substituição de variáveis, resolução de equação e inequação, resolução de sistema de equação, evidenciadas enquanto estrutura de resolução.

Os estudantes poderão ou não fazer uso da representação tabular para simular o comportamento dos fenômenos e representá-los graficamente no eixo cartesiano. Essas condutas, necessariamente, não vão ocorrer nessa ordem, pois os estudantes podem trocar informações, completando o modelo um do outro, sugerindo mudanças até chegar a uma proposta que seja aceita por todos e que contemple o que foi exposto enquanto atividade cognitiva.

Na etapa de validação, cada grupo deve apresentar no quadro a solução das situaçõesproblema, justificando a proposta de resolução. Neste momento, os demais grupos poderão aceitar ou refutar a proposta do grupo que apresenta e pedir explicações, com outras propostas de resolução. Espera-se que os estudantes cheguem a um modelo de resolução parecido, com variações de estratégias que não alterem a estrutura global da resolução, mas que possam se complementar com diferentes apresentações para a mesma situação. Cada dupla, no entanto, pode validar a sua resolução por meio de processo de verificação em cada tarefa. Os estudantes validam as propostas a partir das comparações entre os modelos apresentados. Neste caso, as 


\section{HORIZONTES - REVISTA DE EDUCAÇÃO}

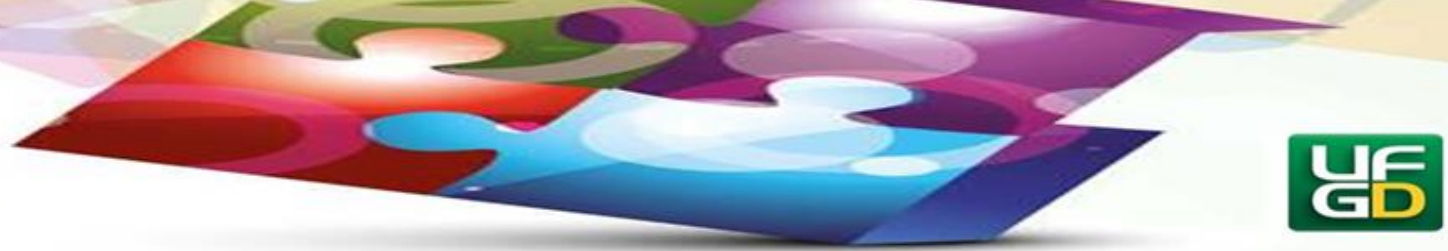

condutas de cada grupo poderão ser diferentes, o que será decisivo na escolha da solução do problema.

Os estudantes, por meio de uma proposta de verificação de sistemas de equações e de equações, podem validar seu modelo de resolução, substituindo os valores encontrados nas equações, e perceber a igualdade de valores.

A dialética de institucionalização poderá ser realizada em duas fases: na primeira, o professor (pesquisador) retoma as situações-problema, explicando, justificando e clarificando os possíveis equívocos na resolução, estabelecendo um parâmetro geral da resolução que contemple a todos, discutindo a estrutura matemática organizada por eles. Num segundo momento, o professor deverá apresentar, usando quadro branco ou datashow, as principais características da função afim, a função linear como caso particular da função afim, além da representação gráfica de cada uma e as relações entre os coeficientes e as variáveis x e y.

Um outro aspecto fundamental na aplicação da sequência didática são as variáveis didáticas escolhidas, para cada atividade, identificamos as seguintes variáveis didáticas, categorizadas no quadro 03.

Pressupomos a interferência das variáveis (ver quadro 3) no processo de resolução/aprendizagem do conceito de função afim e função linear, na perspectiva de que os estudantes mobilizem esquemas relacionados à estruturação de equação, inequação e sistema de equações de primeiro grau, traçando estratégias para resolvê-las. Espera-se que esses esquemas já estejam assentados na estrutura cognitiva dos sujeitos, visto que repousam em conceitos matemáticos prévios, básicos para estudantes de um curso de licenciatura em matemática (equações, inequações, sistemas de equações, substituição de valores).

Pressupomos a interferência das variáveis no processo de resolução/aprendizagem do conceito de função afim e função linear, na perspectiva de que os estudantes mobilizem esquemas relacionados à estruturação de equação, inequação e sistema de equações de primeiro grau, traçando estratégias para resolvê-las. Espera-se que esses esquemas já estejam assentados na estrutura cognitiva dos sujeitos, visto que repousam em conceitos matemáticos prévios, básicos para estudantes de um curso de licenciatura em Matemática (equações, inequações, sistemas de equações, substituição de valores).

Após a experimentação dessa etapa da sessão 1, realizamos a análise a posteriori da atividade 1 e 2 . Nesta análise, destacamos as produções textuais dos estudantes. Ressaltamos 


\section{HORIZONTES - REVISTA DE EDUCAÇÃO}

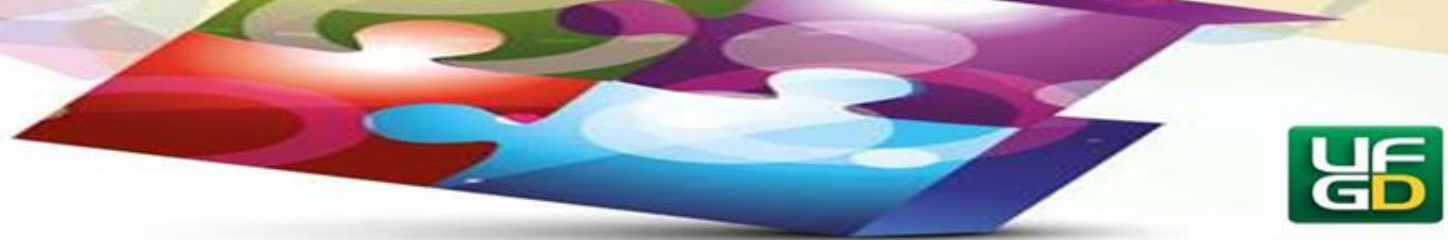

que a experimentação foi realizada no laboratório de informática, e os estudantes fizeram uso da interface digital do Geogebra e do Ambiente Virtual de Aprendizagem (AVA) disponível na página da universidade. Para essa análise, selecionamos os protocolos de duas duplas, buscando confrontar as produções dos sujeitos com as previsões realizadas na análise a priori, ressaltando os aspectos que diferem daquilo previsto.

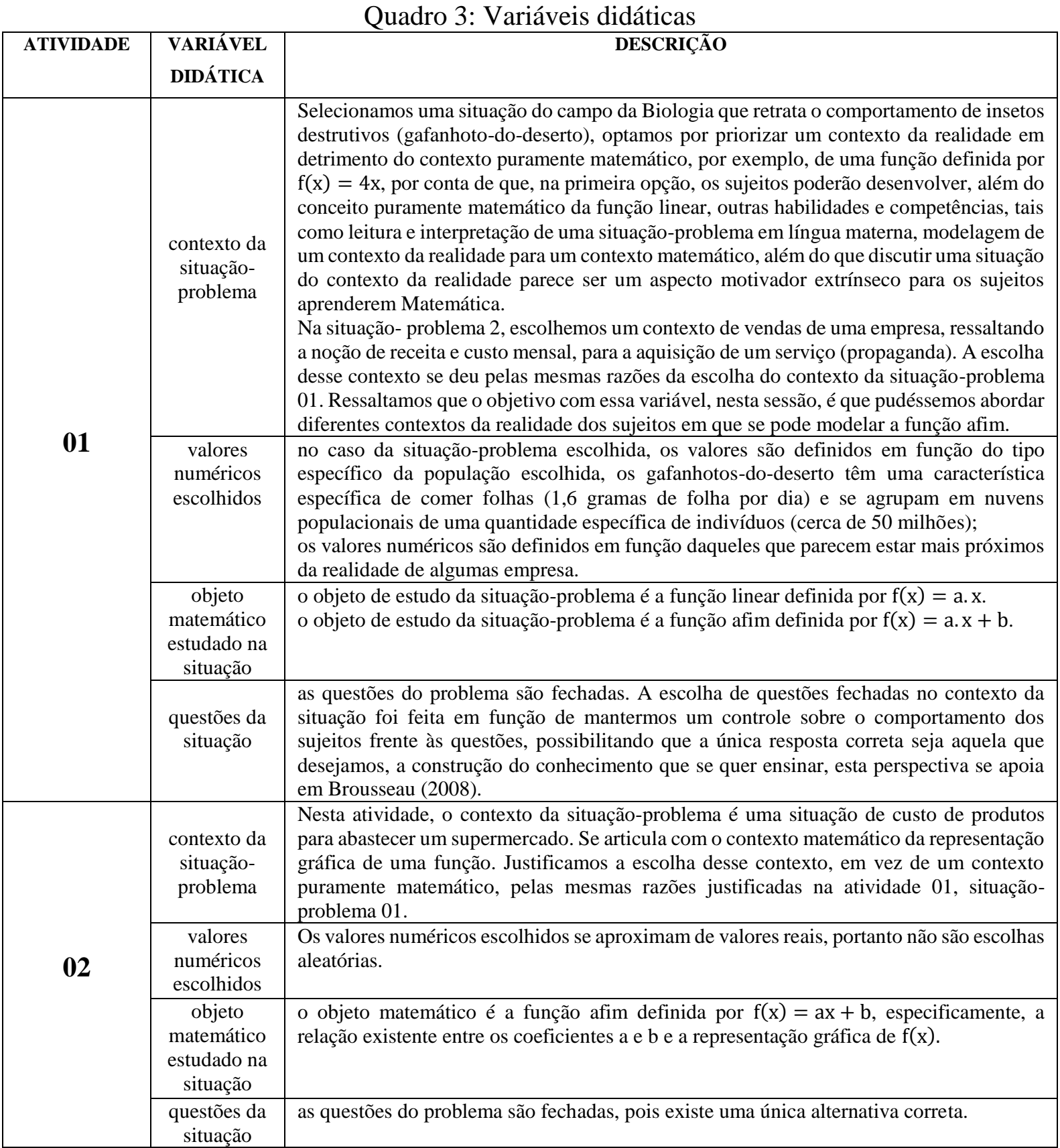

Fonte: Adaptado de Freitas (2015). 


\section{HORIZONTES - REVISTA DE EDUCAÇÃO}

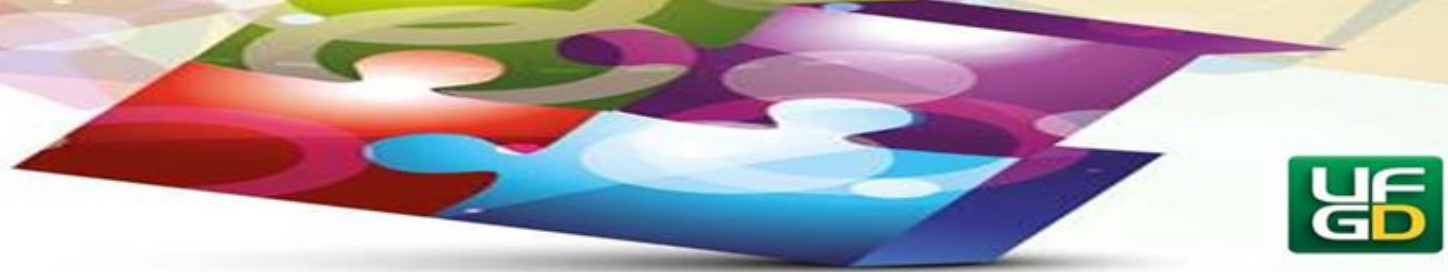

Na análise da atividade 1, na situação problema 1, a dupla A apresentou dificuldade na interpretação do problema. Eles fizeram várias leituras para melhorar o entendimento. Os estudantes não utilizaram de forma direta a definição de função linear, mesmo assim, encontraram um resultado satisfatório. Eles utilizaram como estratégia a regra de três simples, algo que havíamos previsto. Na justificativa sobre o modelo utilizado, a dupla respondeu como se esse modelo fosse pensado para trabalhar com seus alunos de estágio, do Ensino Médio: "Para o aluno utilizar esse modelo matemático apresentado por nós, ele deve interpretar o enunciado da questão. Sim, é possível representar graficamente, pois temos duas variáveis, uma independente e a outra dependente" (DUPLA A) ${ }^{4}$. Apesar de responder que sim para construção do gráfico, a dupla A não o construiu, parece que entendeu não ser necessário tal construção. A dupla A apresentou sua solução conforme descrita na figura 3, na qual se percebe o uso da regra de três.

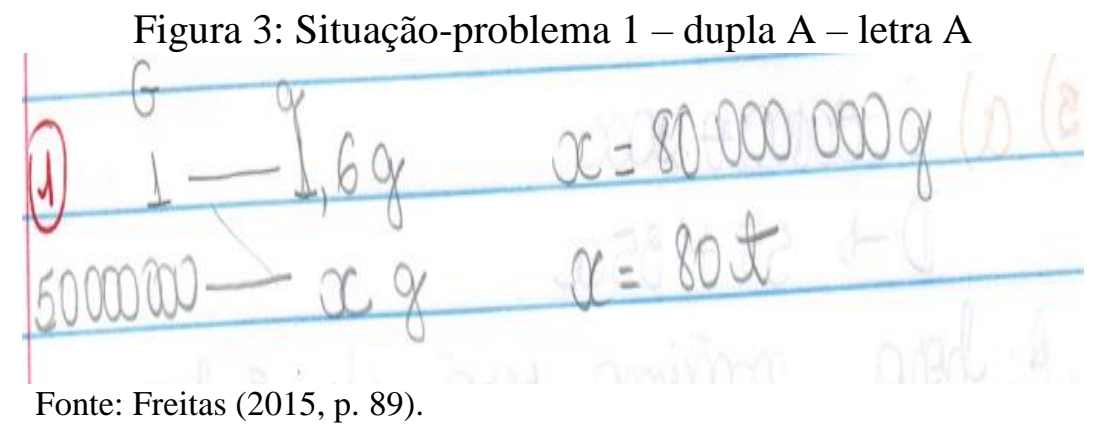

A dupla B desenvolveu o mesmo procedimento que a dupla anterior, mas com algumas diferenças: eles montaram uma estrutura de equação, apresentaram como justificativa a proporcionalidade, usaram a mesma regra de três, como pode ser observado na figura 4.

\footnotetext{
${ }^{4}$ A fim de identificar os estudantes estagiários sem expor seus nomes, foi utilizado o termo “dupla' seguido de uma letra (A, B, C...). Os textos dos estudantes foram transcritos em itálico.
} 


\section{HORIZONTES - REVISTA DE EDUCAÇÃO}

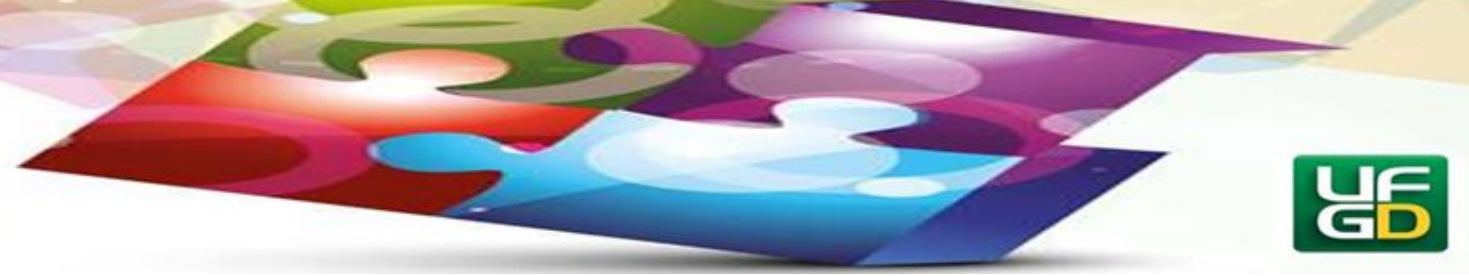

Figura 4: Situação-problema 1 - dupla B - letra A

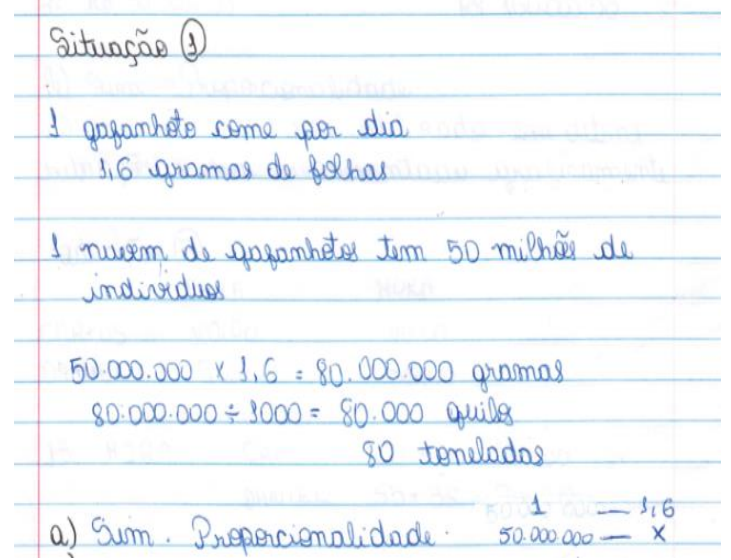

Figura 5: Situação-problema 01 - dupla B letra B

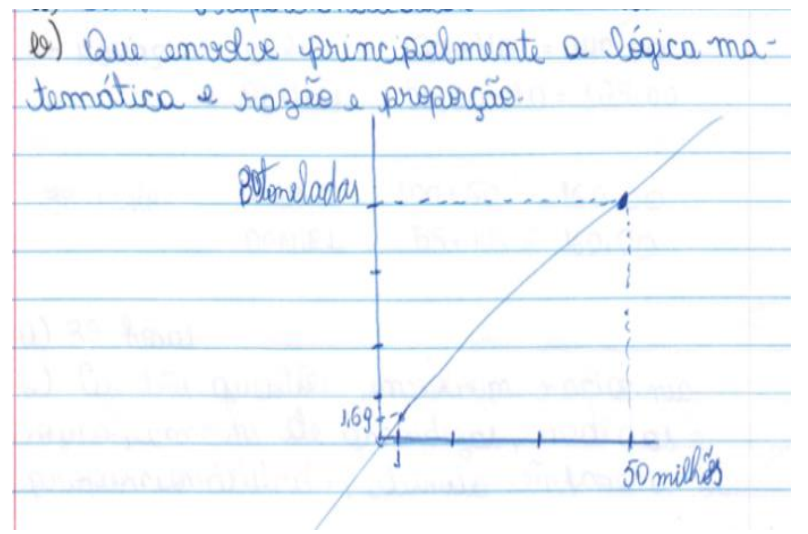

Fonte: Freitas (2015, p. 90).

Para a letra $\mathrm{B}$, a dupla respondeu: "que envolve principalmente a lógica matemática e razão e proporção" (DUPLA B). A representação gráfica (figura 5) realizada pela dupla indica que estão considerando a relação de dependência entre as grandezas, embora não tenham evidenciado explicitamente a lei de formação da função linear: $\mathrm{m}(\mathrm{q})=1,6$ q, além disso, o gráfico está incoerente.

Na situação-problema 02, a dupla A procedeu da mesma maneira da situação-problema 01. Essa dupla apresentou, como no caso da situação-problema 1, a mesma dificuldade relacionada à interpretação das informações contidas no enunciado e em relacionar o contexto da situação ao modelo de função afim. Discutiram muitos resultados pela suposta "lógica" e, depois de um tempo de reflexão, resolveram usar o modelo de proporção de grandezas, regra de três, montando uma estrutura de equação para os gastos e para a receita (figura 6). Para as letras B e C, responderam apenas que sim e que usaram proporção e porcentagem. Os estudantes, até então, em nenhum momento, explicitaram conscientemente os conceitos de função. 


\section{HORIZONTES - REVISTA DE EDUCACÃOO}

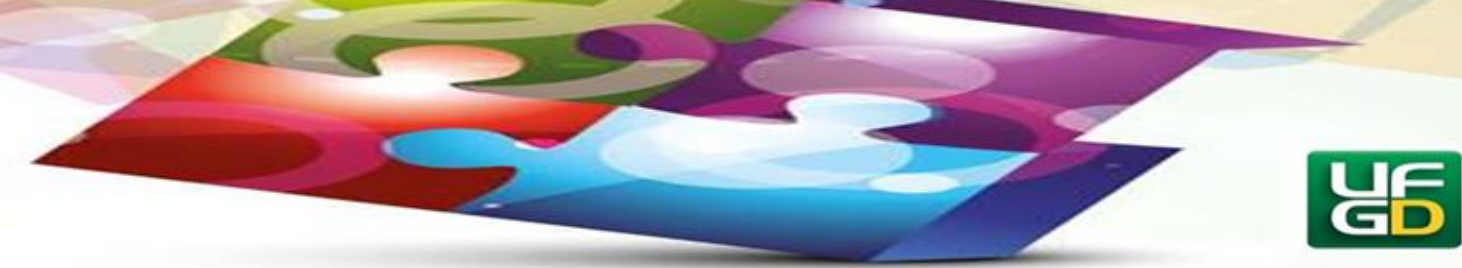

Figura 6: Situação-problema 02 - dupla A

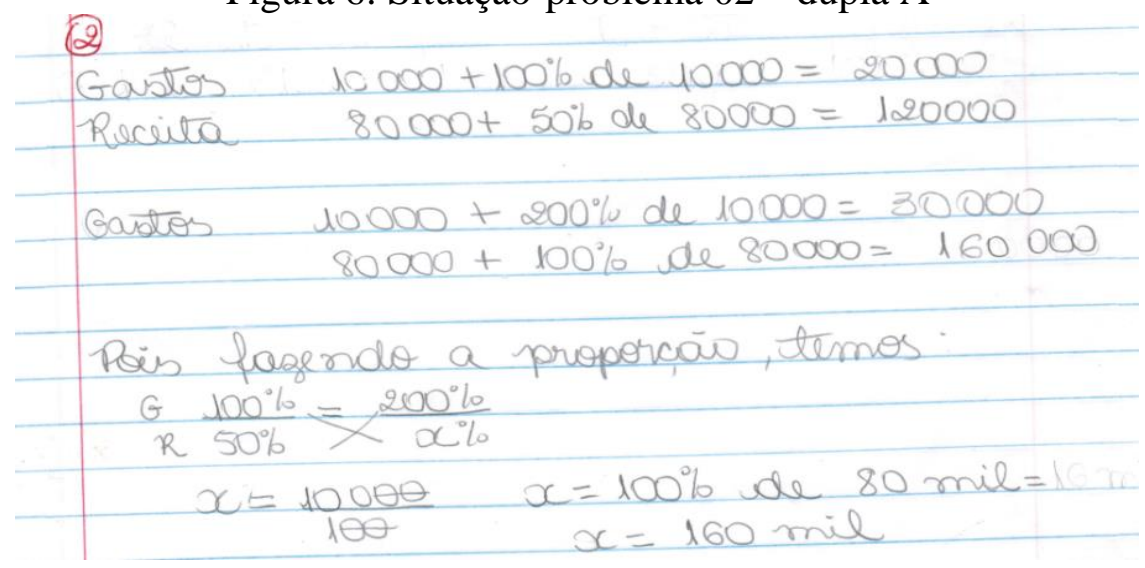

Fonte: Freitas (2015 p. 91).

A dupla B escreveu vários resultados, mas não operou com nenhum modelo matemático, justificou, na letra (B), que usou a proporção e respondeu na letra (C): "que ele pode ser utilizado em outras situações e ser representado graficamente”. É possível inferir que os sujeitos conseguem agir sobre a situação, interagir com o meio, mas não conseguem explicitar um modelo matemático condizente com o modelo de função afim.

Na situação- problema 3, a dupla A escreveu um polinômio do primeiro grau (100+ 20x e 55+35x), no entanto, não definiu uma relação funcional, nem apresentou uma resposta às questões apresentadas. Neste caso, não foi possível perceber como os estudantes resolveram a situação. Sobre a justificativa para as situações-problema, relataram o ponto em comum entre as três situações: a utilização do conceito de proporção. A dupla B responde de forma semelhante à anterior, inclusive na justificativa: "as três questões envolvem raciocínio lógico, conceitos de grandezas, medidas e proporcionalidade, dando ênfase à leitura e interpretação dos textos".

Concluímos que, nas três situações, os estudantes, na etapa de formulação e validação, não estabeleceram nenhuma interação com o saber sobre o conceito de função afim e linear. Apenas no momento da institucionalização, perceberam que se tratava de função afim e linear. Os sujeitos recorreram a outras estratégias como regra de três e proporcionalidade. No nosso ponto de vista, esta conduta revela que, embora os estudantes estejam na fase final da licenciatura, ainda manipulam o conhecimento matemático de forma bem elementar. 


\section{HORIZONTES - REVISTA DE EDUCAÇÃO}

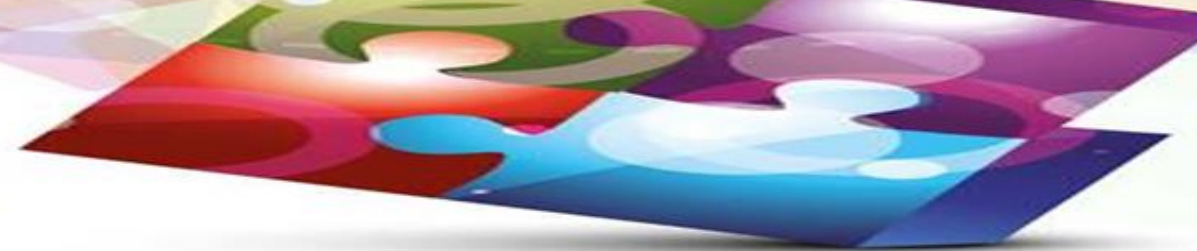

Os nossos objetivos, com essas atividades foram atendidos parcialmente, pois os sujeitos ainda não conseguiam mobilizar as técnicas relacionadas à manipulação de variáveis, construção de gráficos e resolução de sistemas de equação de primeiro grau, mas conseguiam, mesmo com dificuldade, interpretar textos em linguagem natural, sem relacionar o conceito de função.

A partir do fato de que os estudantes não utilizaram as técnicas que pensamos na análise a priori, para resolução das tarefas, as variáveis escolhidas interferem no processo de aprendizagem dos estudantes, mas não da forma como pressupomos. Os estudantes utilizaram como técnica para resolução da tarefa a regra de três simples e o conceito de proporcionalidade, e não aquelas estratégias (desenvolvimento da técnica) que previmos (equações, inequações, sistemas de equações, substituição de valores).

$\mathrm{Na}$ etapa de institucionalização, propomos as referidas técnicas como possibilidades de resolução diferentes daquelas propostas por eles. Com relação à validação desta etapa da sessão de ensino, destacamos como ponto forte a percepção, por parte dos sujeitos, quanto ao modelo de função afim e linear e suas formas de representação.

Julgamos que, em certos aspectos da atividade, houve limitações frente às escolhas realizadas, como, por exemplo, não ter previsto o uso da regra de três como técnica, ter deixado aberta a questão quanto à necessidade e construção ou não do gráfico. Acreditamos que os sujeitos não validaram as estratégias que utilizaram, e sim, o que foi proposto na tarefa e explicitado na institucionalização. No entanto, o trabalho cognitivo realizado por eles sobre proporção contribuiu para a validação das estratégias propostas na tarefa quando aliadas ao processo de institucionalização.

Assim, podemos concluir globalmente que o aporte das variáveis didáticas escolhidas contribuiu para o trabalho cognitivo dos estudantes, no sentido de que relacionaram as estratégias de resolução da situações-problema com os conceitos de função afim e linear.

Quanto à atividade 2, segundo o quadro 4, o objetivo foi relacionar o coeficiente b com o comportamento da função definida, em $\mathbb{R}$, por $f(x)=a x+b$, com a e b sendo número reais e, mais especificamente, perceber o comportamento do gráfico em função do valor de b. Além disso, pretende-se comparar diferentes funções representadas em um mesmo eixo cartesiano e por suas leis de formação. 


\section{HORIZONTES - REVISTA DE EDUCAÇÃO}

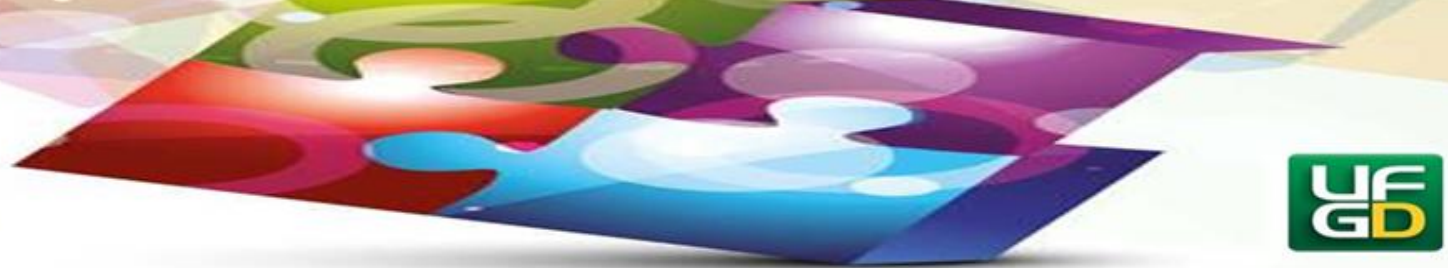

Para a resolução do item (A), é necessário realizar a leitura do enunciado do problema e, em seguida, identificar a organização matemática em torno do conceito de função afim. Temos uma situação que envolve duas funções, uma em relação ao produto A e outra em relação ao produto $\mathrm{B}$, cujas leis de formação são, respectivamente, $\mathrm{C}(\mathrm{k})_{\mathrm{A}}=2,90 \mathrm{k}+210$ e $\mathrm{C}(\mathrm{k})_{\mathrm{B}}$ $=3 \mathrm{k}+200$. Para verificar qual proposta é a mais vantajosa, basta fazer a diferença entre as duas leis de formação $\mathrm{C}(\mathrm{k})_{\mathrm{A}}-\mathrm{C}(\mathrm{k})_{\mathrm{B}}=-0,10 \mathrm{k}+10$. Se $\mathrm{k}$ for menor que 100 , então $\mathrm{C}(\mathrm{k})_{\mathrm{A}}$ é mais vantajosa, e se $\mathrm{k}$ for maior que 100 , então $\mathrm{C}(\mathrm{k})_{\mathrm{B}}$ é mais vantajosa. Se $\mathrm{k}$ for igual a 100 , o custo das duas ofertas é igual.

No item (B) da atividade 2, o gráfico (a) representa os custos do supermercado com fornecedores, pois os pontos de coordenadas $(0,210)$ e $(0,200)$ verificam, respectivamente, as equações $\mathrm{C}(\mathrm{k}) \mathrm{A}$ e $\mathrm{C}(\mathrm{k}) \mathrm{B}$, e o ponto de coordenadas $(100,500)$ é a intersecção das duas retas que representam os dois custos. No item (C), pode-se chegar à conclusão de que esses valores, 210 e 200, são os custos fixos dos produtos e representam os valores dos coeficientes lineares ou termos independentes das funções polinomiais do primeiro grau definidas por $\mathrm{C}(\mathrm{K})_{\mathrm{A}} \mathrm{e}$ $\mathrm{C}(\mathrm{K})_{\mathrm{B}}$, respectivamente.

\section{Quadro 4: Descrição da Atividade 2}

\section{ATIVIDADE 02}

Um fornecedor A oferece a um supermercado certo produto com os seguintes custos: $\mathrm{R} \$ 210,00$ de frete, sendo que são cobrados $\mathrm{R} \$ 2,90$ por cada quilograma do produto. Um fornecedor B oferece o mesmo produto, cobrando $\mathrm{R} \$ 200,00$ de frete, sendo o valor do produto, por quilograma, $\mathrm{R} \$ 3,00$.

(A) Qual a proposta mais vantajosa? (B) Qual dos gráficos a seguir representa os custos do supermercado com fornecedores? (C) Que conclusões você pode chegar em relação aos valores 210 e 200, olhando o gráfico? (SOUZA, 2010, p.91, adaptação nossa).
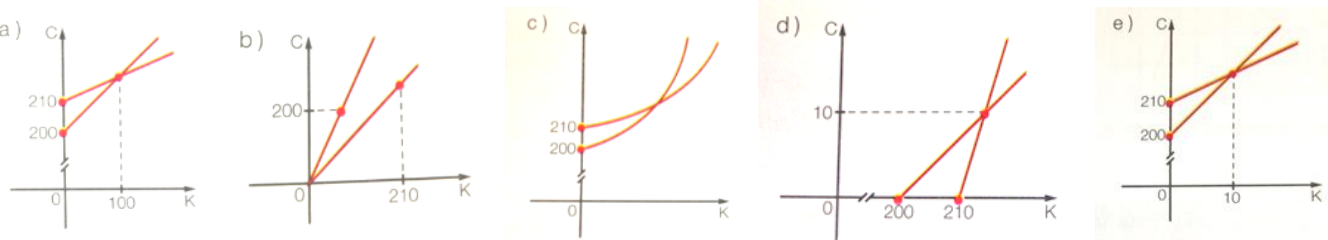

Fonte: Freitas (2015, p. 94).

Propomos uma complementação do estudo proposto na atividade 1, trazendo uma abordagem gráfica e algébrica das funções, na qual o aprendiz possa identificar o ponto de intersecção das duas funções, estabelecendo uma relação entre a representação algébrica e a representação gráfica, por meio dos coeficientes das funções. O estudante deverá perceber que 


\section{HORIZONTES - REVISTA DE EDUCACÃ̃O}

o ponto notável do gráfico $(0, b)$ representa o ponto inicial da reta, e que a partir de dois pontos do gráfico (da reta) é possível determinar sua lei de formação definida pelo modelo $f(x)=a x$ $+\mathrm{b}$.

Do ponto de vista didático (análise didática), em dialética de ação, os estudantes irão agir de forma semelhante à atividade anterior (atividade 01), sobre a situação, de forma que ela lhes retorne informações sobre sua ação. A partir de então, os alunos elaboram uma representação para sintetizar os dados e estabelecer uma estratégia de resolução.

Em uma etapa de formulação, os estudantes poderão adotar algumas condutas, a partir das seguintes informações levantadas na etapa de ação: $\mathrm{C}(\mathrm{k})_{\mathrm{A}}=2,90 \mathrm{k}+210$ e $\mathrm{C}(\mathrm{k})_{\mathrm{B}}=3 \mathrm{k}+200$. Eles podem, por exemplo, explicitar as etapas da resolução da atividade, a partir da relação entre os termos independentes das funções $\mathrm{C}(\mathrm{K})_{\mathrm{A}}$ e $\mathrm{C}(\mathrm{K})_{\mathrm{B}}$, respectivamente 210 e 200, com os pontos de intersecção $(0,210)$ e $(0,200)$, com o eixo $y$, identificando, assim, os gráficos que correspondem às funções dadas. Ou seja, em toda função afim, o ponto de coordenadas $(0, b)$ sempre toca o eixo y, e o ponto de coordenadas (-b/a, 0) sempre toca o eixo x.

$\mathrm{Na}$ dialética de validação, os estudantes podem atribuir valores para $\mathrm{k}$ e encontrar os gráficos das funções $\mathrm{C}(\mathrm{K})_{\mathrm{A}}$ e $\mathrm{C}(\mathrm{K})_{\mathrm{B}}$ idênticos àqueles por eles identificados na atividade proposta, submetendo esta estratégia à apreciação dos colegas. Na institucionalização, é discutido com a professora/pesquisadora o conceito de função afim e função linear, suas propriedades e as representações gráficas, reforçando o que foi discutido na atividade 01 .

Após o desenvolvimento da atividade 2, realizamos análise a posteriori, na qual identificamos que a dupla A apresentou dificuldade na hora de analisar o gráfico e, também, para decidir qual a proposta era a mais vantajosa. Resolveu a situação de forma diferente da que previmos. No entanto, percebemos uma mudança no comportamento dos estudantes no que se refere à manipulação das variáveis independente e dependente, x e y respectivamente, e na representação do modelo matemático coerente com a função afim, a partir da leitura da situação problema, algo não identificado na atividade 1, mas previsto para etapa de ação e formulação. 


\section{HORIZONTES - REVISTA DE EDUCAÇÃO}

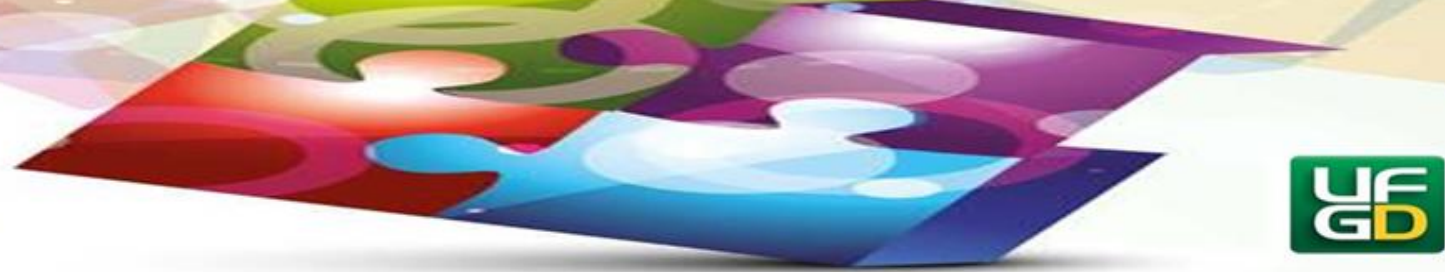

Figura 7: Atividade 02 - dupla A

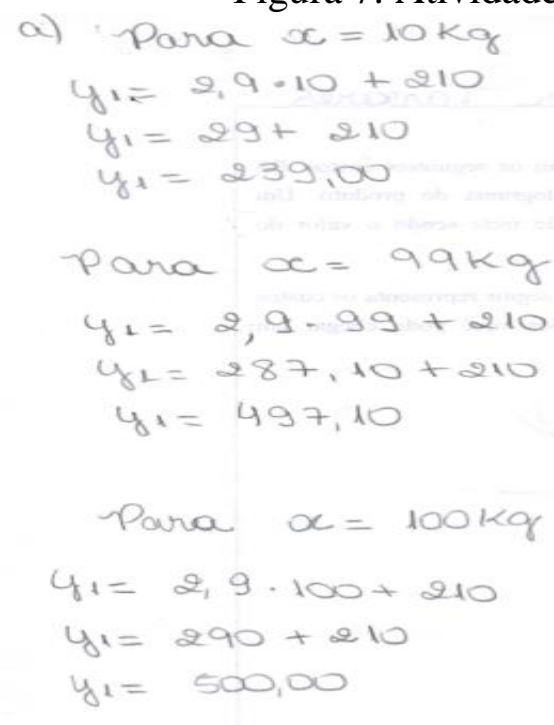

Fonte: Freitas (2015, p. 96).

Após analisar a construção, por meio da figura 5 e das respostas fornecidas pelos estudantes, concluímos que, apesar de identificar os coeficientes lineares das leis de formação das funções, os estudantes apontaram o gráfico incorreto, o que significa que ainda não perceberam a relação entre os coeficientes das funções e suas representações gráficas.

A dupla B utilizou as mesmas estratégias de substituição de valores que a dupla A, no entanto, explicou a relação entre os coeficientes das funções e os gráficos, apontando a alternativa correta. Durante a institucionalização, os estudantes puderam clarificar as dúvidas e perceber que adaptações poderiam ser realizadas no modelo de solução por eles construído.

Nessa atividade, escolhemos modelar a função afim a partir de um contexto de situação-problema em linguagem natural, articular a representação do modelo algébrico construído com a sua representação gráfica, perceber e analisar a importância do coeficiente linear da função (termo b) para a representação gráfica de uma função afim.

Em termos da resolução/aprendizagem da atividade, na fase adidática, os estudantes conseguiram articular representação do modelo da função afim, de forma algébrica, o que representa uma evolução em relação à atividade 01 . No entanto, não conseguiram ainda articular a representação algébrica construída por eles com a representação gráfica adequada.

A partir disso, intervimos na etapa de institucionalização da tarefa, discutindo com os estudantes os modelos gráficos, os quais se adequavam ao modelo algébrico construído por ele 


\section{MORIZONTES - REVISTA DE EDUCAÇÃO}

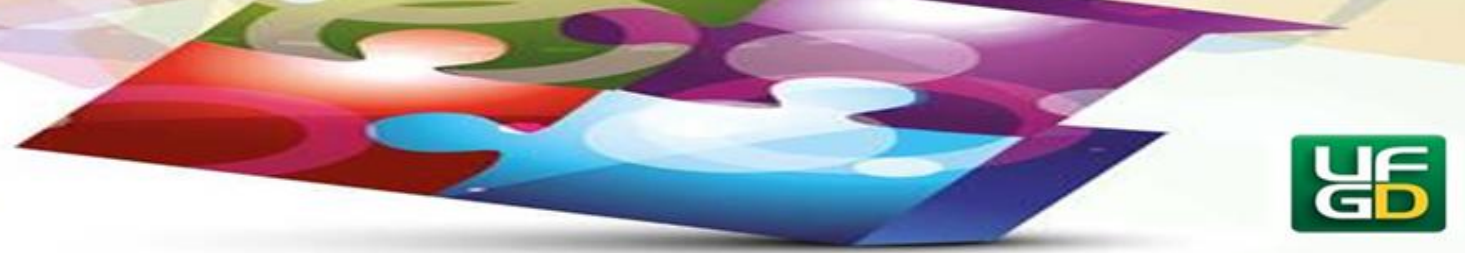

e destacando a relação existente entre o coeficiente linear e a representação gráfica da função afim.

Destacamos como pontos fortes, em termos de validação interna da sessão, que os estudantes: identificaram a variável x como dependente de y, e os valores de b enquanto variável independente da função afim; associaram o modelo algébrico da função afim a partir de um contexto de situação-problema em língua natural. Tais constatações nos levam a concluir que os estudantes começam a apresentar uma modificação de comportamento frente ao saber que está em jogo. Por outro lado, a escolha de associar um modelo algébrico construído por eles a um modelo gráfico apresentado não facilitou a articulação da representação algébrica com a representação gráfica da função afim, pois os estudantes não conseguiram identificar o gráfico correto. Nesse sentido, a institucionalização foi fundamental para reforçar a compreensão da representação gráfica da função afim.

Globalmente, a questão do problema "perceber o comportamento do gráfico da função afim, em termos do coeficiente linear b" nos dá o aporte necessário para discutir, na etapa de institucionalização, a técnica de resolução da tarefa. Isto se confirma quando os estudantes explicitam verbalmente que compreenderam a tarefa e mudam seu comportamento frente aos saberes em jogo.

Do ponto de vista epistemológico, o breve estudo da função afim contribuiu para o conhecimento científico dos estudantes sobre a evolução do conceito de função. Por outro lado, a natureza das situações-problema pode influenciar socio-culturalmente a visão dos sujeitos frente aos problemas de devastação do meio ambiente, problemas econômicos do cotidiano e de finanças pessoais. Enfim, os estudantes resolvem problemas da realidade socioeconômica e desenvolvem modelos matemáticos de funções.

Concluímos que, nessa atividade, apesar de os estudantes já saberem que estavam trabalhando com a função afim, não demonstraram explicitamente a relação entre os coeficientes e seu comportamento no gráfico, enquanto coordenadas de pontos das retas que representam as funções. Por outro lado, eles utilizaram a manipulação das variáveis, por meio da substituição como uma das técnicas que previmos.

Os objetivos para a primeira sessão foram alcançados, no sentido de que se proporcionou aos estudantes refletir em torno de situações que envolviam os conceitos de função linear e afim, que são importantes no que diz respeito à construção de gráficos, 


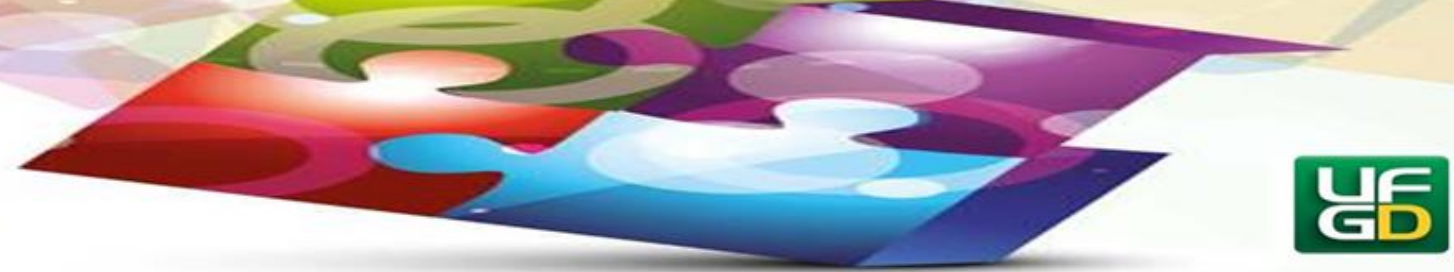

manipulação de variáveis dependentes, ao estudo de coeficientes da lei de formação de função e sua relação com a representação gráfica.

Os resultados obtidos reforçam a ideia de que os estudantes recorrem a conceitos fundamentais, como proporcionalidade e técnicas como regra de três simples, resolução de equação, em detrimento do conceito de função e de suas representações, trabalhados na licenciatura. Parece que, mesmo os estudantes tendo cursado diversos componentes curriculares de cálculo envolvendo funções de uma forma geral, quando sua aplicabilidade se faz necessária, esses conhecimentos não são mobilizados na solução de tarefas.

Analogamente, o trabalho com a função exponencial poderá contribuir para também ressignificar conceitos ligados à função, às técnicas de resolução de situações sobre função e tipos de representações, a exemplo da representação tabular e gráfica.

\section{Autoavaliação reflexões sobre os principais resultados}

No que se refere à autoavaliação do desenvolvimento do projeto, é importante retomar o problema inicial motivador, na perspectiva de elucidar os principais resultados apresentados destacando importância destes últimos para: o desenvolvimento profissional da professora /pesquisadora, a formação dos licenciandos (estagiários) do curso de Licenciatura em Matemática para a instituição participante do projeto, os limites, possibilidades e contribuições do projeto para a área de pesquisa em Educação Matemática.

A proposta do trabalho pedagógico de sala de aula com a turma de Estágio Supervisionado IV, aliada ao trabalho de pesquisa proposto com o grupo PEAMAT trouxe uma importante contribuição para a formação da docente como pesquisadora no sentido se aliar ensino e pesquisa e reaproximar a prática profissional na universidade com as atividades da escola regular. Além disso, as reflexões teóricas e acerca das limitações da pesquisa, contribuíram fortemente na formação da pesquisadora.

Para formação inicial do licenciandos, os resultados do projeto indicam que os estudantes despertaram para uma nova prática. Perceberam a importância do estudo dos objetos matemáticos no Estágio Supervisionado aliado ao estudo dos saberes didáticos a serem desenvolvidos na Educação Básica. Nessa perspectiva, na atuação profissional, esses estudantes 


\section{HORIZONTES - REVISTA DE EDUCAÇÃO}

e-ISSN: 2318-1540

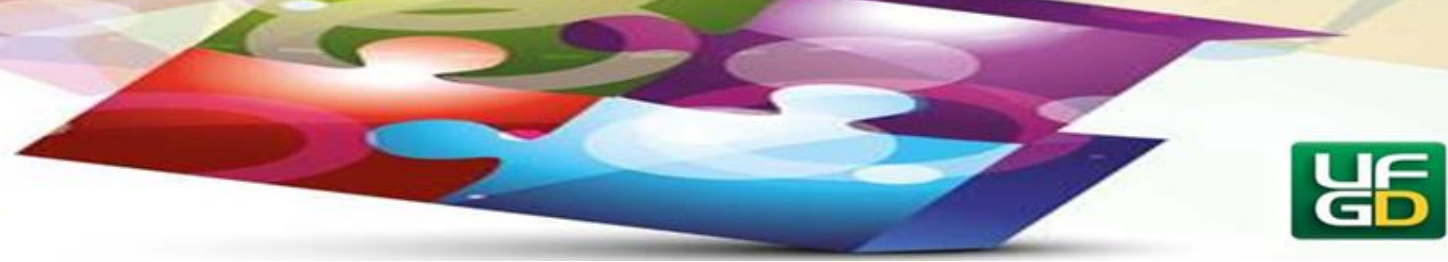

poderão implementar novas práticas de ensino, melhorado a qualidade da Educação Básica, para o ensino de Matemática.

Para a universidade a contribuição foi significante, pois retoma o diálogo entre a Educação Básica e os cursos de formação de professores, no sentido de haver uma melhor articulação do conhecimento científico com o conhecimento prático profissional. Além disso, resgata o papel da universidade de fornecer uma formação de qualidade aos futuros professores da Educação Básica.

Em termos de limites da pesquisa, uma possibilidade apontada ao final do projeto foi a de rediscutir a sequência didática elaborada pelos estudantes e aplicá-la nas escolas de Ensino Médio, nas quais estava sendo desenvolvido o estágio, apesar de não ter sido esse o objetivo da intervenção. As dificuldades dos estudantes com a manipulação do software e a falta de organizadores prévios dos conteúdos matemáticos básicos, dificultou a realização determinadas tarefas, necessitando uma maior intervenção da professora/pesquisadora nas etapas de institucionalização.

Detectamos que os estudantes não dominavam vários dos conceitos prévios, estruturantes e organizadores de um quadro mínimo de conceitos, ou em termos de domínio de técnicas para determinadas tarefas, por exemplo: resolver um sistema de equações e inequações do primeiro grau, compreender o conceito de par ordenado, escalas e resolver equações. São conhecimentos necessários para a manipulação matemática com funções exponenciais ou a função afim. Os estudantes demonstraram certo grau de fragilidade em seu repertório cognitivo sobre esses temas.

De acordo com os resultados da análise dos dados coletados, estes estudantes mobilizam conceitos em um nível que consideramos muito básico para o estagiário da licenciatura, já em uma etapa de conclusão de curso. Ou seja, o nível de conhecimentos que, inicialmente, eles mobilizaram, poderia ser comparado com o de um estudante do Ensino Fundamental II ( $6^{\circ}$ ao $9^{\circ}$ ano); no entanto, o desenvolvimento da sequência didática promoveu certo amadurecimento dos estudantes diante dos seus processos de aprendizagem, no sentido de perceber que precisam investir mais no conhecimento matemático. Esta conclusão baseia-se nos diferentes relatos explicitados pelos estudantes sobre as atividades promovidas pelo projeto de pesquisa. 


\section{MORIZONTES - REVISTA DE EDUCACÃ̃O}

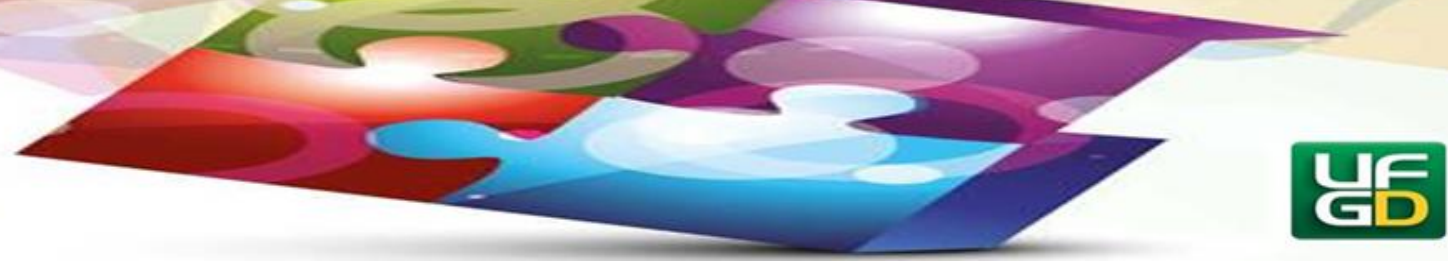

No que se refere aos saberes docentes, que são evidenciados nas respostas dos estudantes na quinta sessão, inferimos que ainda se apresentam mais acentuados, do ponto de vista pedagógico que do ponto de vista didático. Percebemos uma falta de articulação entre o conhecimento matemático, recentemente construído por eles, e a construção de uma proposta de intervenção didática efetiva, na realidade de seus supostos alunos. Suas falas indicam que não articulam ou relacionam os saberes matemáticos com os saberes pedagógicos já adquiridos por eles, tais como: plano de aula, metodologia de ensino, recursos didáticos e materiais, habilidades específicas dos estudantes. No entanto, há indícios de que os estudantes têm certo domínio em relação ao conceito de planejamento, pelo menos no que se refere a suas etapas.

Possivelmente, estes conhecimentos pedagógicos podem ter sido construídos nos componentes curriculares das Ciências da Educação, mais especificamente, durante o Estágio Supervisionado. No entanto, o desconhecimento de elementos básicos da didática da Matemática, tais como conceito de contrato didático e de transposição didática, pode estar impossibilitando os estudantes de elaborar uma proposta clara de intervenção na realidade dos alunos do Ensino Médio. Consideramos prudente indicar estas questões a novas análises e novas pesquisas, pois extrapolam o foco do nosso trabalho.

O que podemos afirmar, levando em consideração Pires (2012), e a partir dos resultados levantados em nossa pesquisa, é que, de fato, a licenciatura em matemática nas IES baianas não consegue desenvolver os saberes docentes inerentes à formação inicial dos professores de Matemática. Além disso, as propostas de Estágio Supervisionado precisam ser ressignificadas sob o ponto de vista de contribuir na consolidação desses saberes docentes, em que pese que, somente na atuação profissional, estes futuros professores terão uma formação mais completa, por meio da construção dos saberes experienciais.

\section{Referências}

ALMOULOUD, S. A. Fundamentos da didática da matemática. Curitiba: Ed. UFPR, 2007.

ARTIGUE, M. Ingèniere didactique. RDM, v.9, n.3, p.231-308, 1988.

BRITO, A. de J.; ALVES, F. T. O. In: NACARATO, A. M.; PAIVA, M. A. V. A formação do professor que ensina matemática: perspectivas e pesquisas. Belo Horizonte: Autêntica, 2006. 


\section{HORIZONTES - REVISTA DE EDUCAÇÃO}

e-ISSN: 2318-1540

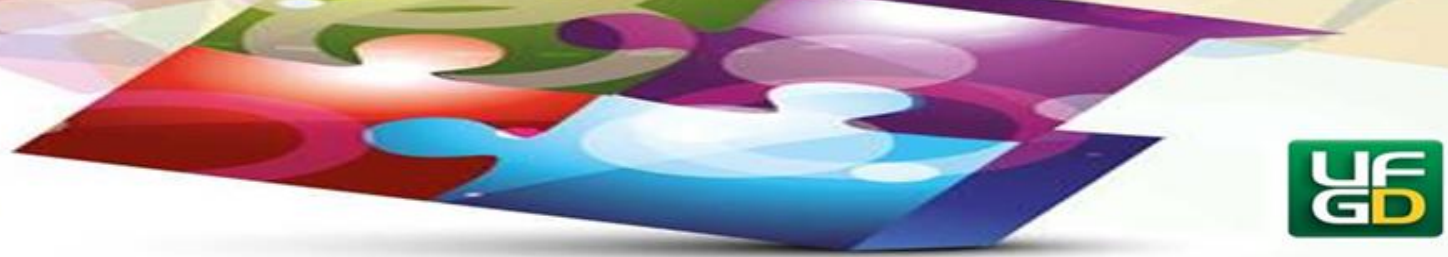

BROUSSEAU, G. Fundamentos e métodos da didáctica da matemática. In: BRUN, J.

Didáctica das matemáticas. Lisboa: Editora Horizontes Pedagógicos, 1996.

BROUSSEAU, G. Introdução ao estudo das situações didáticas: conteúdos e métodos de ensino. São Paulo: Editora Ática, 2008.

CHEVAlLARD, Yves. El Análisis de Las Prácticas Docentes en la Teoría Antropológica De Lo Didáctico. Recherches em Didactique dês Mathématiques, v. 19, n. 2, p. 221-266, 1999.

DUVAL, R. L'analyse cognitive du fonctionnement de la pensée et de l'activité mathématique: cours sur apprentissages intellectuels donné à la PUC-SP. São Paulo: Programa de Estudos Pós-graduados em Educação Matemática, 1999.

FREITAS, R. L.; ALMOULOUD, S. A. Representações sobre função exponencial. Anais... XI ENEM. Curitiba, 2013. Disponível em <http://sbem.bruc.com.br/XIENEM/pdf/2226_1095_ID.pdf> Acesso em: 01/08/2013.

FREITAS, R. L. A influência de organizações didáticas no trabalho matemático dos estagiários da licenciatura: um estudo da função exponencial. 2015. 173 f. Dissertação (Mestrado em Educação Matemática) - Pontífica Universidade Católica de São Paulo. São Paulo, 2015.

PIMENTA, S. G.; LIMA, M. S. L. Estágio e docência. São Paulo: Cortez, 2011.

PIRES, M. A. L. M. Estágio curricular supervisionado: uma análise dos cursos de licenciatura em matemática. In: SANTA’ANA, C. de C.; SANTANA, P. I.; EUGÊNIO, B. G. (Orgs.). Estágio supervisionado, formação e desenvolvimento profissional docente. São Carlos: Pedro \& João Editores, 2012.

ROSSINI, R. Saberes docentes sobre o tema função: uma investigação das praxeologias. 2006. 382 f. Tese (Doutorado em Educação Matemática) - Pontífica Universidade Católica de São Paulo. São Paulo, 2006.

TARDIF, M. Saberes docentes e formação profissional. Petropólis: Vozes, 2012.

ZUFFI, E. M. O tema "funções" e a linguagem matemática de professores do ensino médio: por uma aprendizagem de significados. 1999. Tese (Doutorado em Didática) - Universidade de São Paulo. São Paulo, 1999.

ZUFFI, E. M. Uma sequência didática sobre funções para a formação de professores do ensino médio. In: Anais... VIII Encontro Nacional de Educação Matemática. Recife, 2004. CD-ROM.

Enviado :14/07/2018

Aceito : 29/08/2018 